\author{
Universidade de São Paulo \\ Escola de Enfermagem de Ribeirão Preto
}

Marina de Melo Barbosa

Sobrecarga do cuidado em famílias de egressos de internação psiquiátrica - análise nos três meses após a alta hospitalar 
Marina de Melo Barbosa

\section{Sobrecarga do cuidado em famílias de egressos de internação psiquiátrica - análise nos três meses após a alta hospitalar}

Dissertação (Mestrado) apresentada ao Programa de Pós Graduação em Enfermagem Psiquiátrica da Escola de Enfermagem de Ribeirão Preto Universidade de São Paulo, para obtenção do título de Mestre em Ciências .

Linha de pesquisa: Enfermagem Psiquiátrica: o doente, a doença e as práticas terapêuticas.

Área de Concentração: Enfermagem Psiquiátrica Orientadora: Prof ${ }^{a}$ Dr $^{a}$.Sueli Ap. Frari Galera

Ribeirão Preto 
AUTORIZO A REPRODUÇAO E DIVULGAÇAO TOTAL OU PARCIAL DESTE TRABALHO, POR QUALQUER MEIO CONVENCIONAL OU ELETRÔNICO, PARA FINS DE ESTUDOS E PESQUISA, DESDE QUE CITADA A FONTE.

FICHA CATALOGRÁFICA

Barbosa, Marina de Melo

Sobrecarga do cuidado em famílias de egressos de internação psiquiátrica - análise nos três meses após a alta hospitalar. Marina de Melo Barbosa; orientadora: Prof ${ }^{\mathbf{a}}$. Dr ${ }^{\mathbf{a}}$. Sueli Aparecida Frari Galera Ribeirão Preto, 2011.

48p. il; $30 \mathrm{~cm}$,

Dissertação (Mestrado) - Programa de Pós-graduação da Escola de Enfermagem de Ribeirão Preto, Universidade de São Paulo.

Área de concentração: Enfermagem Psiquiátrica

Linha de pesquisa: $\mathrm{O}$ doente, as doenças e as práticas terapêuticas.

1-Enfermagem psiquiátrica; 2- Relações Familiares;

3-Desinstitucionalização 


\section{FOLHA DE APROVAÇÃO}

Barbosa, Marina de Melo

Sobrecarga do cuidado em famílias de egressos de internação psiquiátrica - análise nos três meses após a alta hospitalar.

Dissertação apresentada à Escola de Enfermagem de Ribeirão Preto da Universidade de São Paulo, para obtenção do título de Mestre em Ciências. Área de concentração: Enfermagem Psiquiátrica

Aprovado em:

Banca examinadora

Prof Dr.

Instituição Assinatura:

Prof Dr.

Instituição Assinatura:

Prof Dr.

Instituição Assinatura: 
Por todo apoio, incentivo e amor dedico este trabalho aos meus pais, Elpídio e Sônia e meus irmãos Rodrigo e Douglas! 


\section{Agradecimentos}

À Prof ${ }^{a}$. Dra . Sueli Ap Frari Galera, por seus ensinamentos, orientação, carinho e amizade durante minha trajetória acadêmica.

À Prof ${ }^{\mathrm{a}}$. Dr ${ }^{\mathrm{a}}$. Lucilene Cardoso, pelo conhecimento, disponibilidade, amizade e incentivo em todo processo de desenvolvimento deste trabalho e seus alunos de iniciação científica que contribuíram no processo de coleta de dados.

Aos amigos que colaboraram na construção deste projeto Ana Carolina G. Zanetti, Viviane Rosa, Bianca, Jorge Neto, Fernando Hueb, e meu irmão Rodrigo César.

À Coordenação de Aperfeiçoamento de Pessoal de Nível Superior (CAPES) pela concessão da bolsa de mestrado com apoio financeiros aos meus estudos.

À todos os familiares,pacientes e cuidadores que colaboraram com a elaboração deste trabalho e me ensinaram muito sobre a saúde mental.

A equipe do Núcleo de Saúde Mental, pelo profissionalismo, apoio e amizade, em especial a profissional Ângela Márcia que sempre me proporcionou muitos ensinamentos.

Aos amigos e familiares de Uberaba, Iturama, Araguari e Brasília que mesmo distantes sempre me ajudaram e me apoiaram durante meus estudos.

Aos amigos de Ribeirão Preto que tornaram-se minha família nesta cidade; vibraram comigo em minhas conquistas e foram meu alicerce nos momentos difíceis. 


\section{RESUMO}

BARBOSA, M.M; Sobrecarga do cuidado em famílias de egressos de internação psiquiátrica - análise nos três meses após a alta hospitalar. 48f , Dissertaçao (Mestrado)-Escola de Enfermagem de Ribeirão Preto,Universidade de São Paulo, 2011.

A política de saúde mental preconiza a diminuição da oferta de leitos psiquiátricos e a criação de serviços na comunidade deslocando a responsabilidade pelo seguimento do tratamento da doença mental das equipes hospitalares para as equipes comunitárias, o doente mental e seus familiares. Pacientes com transtornos mentais e seus familiares vivenciam momentos cíclicos de controle e diminuição sobre situações problema, as quais podem ou não resultar em internação psiquiátrica. A família passa a ser a principal provedora de cuidados e apoio aos pacientes psiquiátricos, no meio extra-hospitalar, fator este que pode gerar sobrecarga na família.A sobrecarga familiar é definida como "um estado psicológico que advém da combinação de trabalho físico, emocional e pressão social". O período pós a alta hospitalar pode gerar a família grande impacto que ao longo do tempo se modifica. O presente estudo tem como objetivo descrever e comparar a sobrecarga objetiva e subjetiva do familiar cuidador de pacientes no primeiro mês de alta hospitalar e após três meses deste período. Método - Foi aplicada a escala FBIS-BR nos neste primeiros mês e após três meses deste período. Foram entrevistados 26 familiares de pacientes que realizavam seguimento em um serviço de saúde mental ambulatorial na cidade de Ribeirão Preto. Os dados foram analisados através de freqüência e porcentagem e o teste não paramétrico de Wilcoxon-teste t- foi aplicado para identificar os itens da FIBS-BR que se destacaram na sobrecarga familiar. Resultados e discussão:.Os familiares dos 63 pacientes que compareceram as consultas foram convidados a participar do estudos e destes somente 26 aceitaram participar .Os pacientes desta amostra são em sua maioria homens, casados e completaram o ensino fundamental .Com relação aos cuidadores a maioria eram mulheres e mães com média de idade de 51 anos .Os participantes deste estudo são pertencentes a classe social mais baixa. Os diagnósticos mais prevalentes no estudo foram dos seguintes agrupamentos: "Esquizofrenia, transtornos esquizotípicos,Transtornos delirantes e Transtornos de Humor" .Os resultados demonstraram que a sobrecarga objetiva destaca-se da subjetiva nos dois momentos analisados. Indicando que os familiares são sobrecarregados com atividades de cuidado do doente, porém não se sentem prejudicados por isso. Possivelmente este resultado indica que os familiares preferem responder que não se incomodam porque entendem que é sua obrigação cuidar do familiar.A sobrecarga do cuidado objetiva e subjetiva diminuiu do primeiro para o terceiro mês e três aspectos podem explicar este resultado : 1- Paciente ainda com sintomas da doença no primeiro mês após a alta hospitalar 2- Readaptação da família após três meses de alta hospitalar; 3- Estratégia de visitas domiciliares pela equipe de saúde. Considerações Finais: Este estudo aponta para a importância e necessidade de acompanhamento dos pacientes egressos e seus familiares. A visita domiciliar é uma estratégia importante pois consegue manter um vinculo mais estreito entre o doentes, sua família e o serviços de saúde mental. A visita domiciliar é parte das atividades do enfermeiro sendo portanto, um dos profissionais da equipe que pode contribuir muito para melhorar as condições de doentes e famílias.

Descritores: Enfermagem psiquiátrica; Relações Familiares; Desinstitucionalização. 


\begin{abstract}
BARBOSA, M.M; Burden of care in families of graduates in psychiatric hospitals - analysis within three months after hospital discharge. 48f. - Dissertation (MSc) School of Nursing of Ribeirão Preto, Universidade de São Paulo, 2011

The mental health policy calls for the reduced supply of psychiatric beds and the creation of services in the community by shifting responsibility for monitoring the treatment of mental illness of hospital staff to community teams, the mentally ill and their families. Patients with mental disorders and their families experience moments cyclic control and reduction of problem situations, which may or may not result in psychiatric hospitalization. The family becomes the primary provider of care and support to psychiatric patients in the middle-ofhospital, a factor that can lead to overload in the family. The family burden is defined as "a psychological state that arises from the combination of physical work, emotional and social pressure". The post hospital discharge to the family can generate great impact over time changes. The present study aims to describe and compare the objective and subjective burden of family caregivers of patients in the first month of hospital discharge and after three months of this period. Method - was applied FBIS-BR scale in this first month and after three months of this period. Were interviewed 26 relatives of patients who were performing a follow-up outpatient mental health services in Ribeirão Preto. Data were analyzed using frequency and percentage and the nonparametric Wilcoxon t-test was used to identify items of FIBS-BR that stood out in the family burden. Results and discussion: The relatives of 63 patients who attended the consultations were invited to participate in these studies and only 26 agreed to participate. The patients in this sample are mostly male, married and completed their primary education. With respect to most caregivers were women and mothers with an average age of 51 years. The participants in this study are belonging to lower social class. The most prevalent diagnosis in the study were the following groupings: "Schizophrenia, schizotypal disorder, delusional disorders and mood disorders". The results showed that the overhead lens stands out in two moments of subjective analysis. Indicating that family members are overwhelmed with patient care activities, but do not feel harmed by it. Possibly this result indicates that family members prefer to answer that do not bother because they understand that it is his duty to take care of the family. The burden of care objectively and subjectively decreased from first to third month and three aspects may explain this result: 1 - The patient has symptoms of the disease in the first month after hospital discharge; 2 Hospital - Rehabilitation of the family after three months of hospital discharge; 3 - Strategy of home visits by health teams. Final Thoughts: This study highlights the importance and necessity of patient follow up graduates and their families. The home visit is an important strategy because it can maintain a closer link between the patient, his family and mental health services. The home visit is part of the activities of nurses and therefore, a team of professionals that can do much to improve conditions for patients and families.
\end{abstract}

Keywords: Psychiatric Nursing, Family Relations; Deinstitutionalization. 


\section{RESUMEN}

BARBOSA,M.M. 2011. Sobrecarga de la atención en las familias de los graduados en los hospitales psiquiátricos - Análisis plazo de tres meses tras el alta hospitalaria. - 48f. Tesis (Maestría) Escuela de Enfermería de Ribeirão Preto, Universidad de São Paulo, 2011.

La política de salud mental preconiza la diminuición de la oferta de camas psiquiátricas en hospitales y la creación de servicios en la comunidad cambiando la responsabilidad por el seguimiento. Del tratamiento de la enfermedad mental de los equipos hospitalares para los equipos comunitários, el enfermo mental y su família. Pacientes com trastornos mentales y su família tienen momentos cíclicos. Del control y dizminuicion de situaciones problemáticas, que pueden o no virse a ser una internacion psiquiátrica. La família viene a ser la principal proveedor de cuidados y apoyo a los pacientes psiquiátricos, en el médio extrahospitalar, fator esse que puede generar sobrecarga en la família. La sobrecarga de la família se define como " un estado psicológico que viene de la combinación de trabajo físico, emocional y presion de la sociedad". El período despues de la salida del hospital puede generar a la família gran impacto que mientras se pasa el tiempo se cambia. El presente estúdio tiene como objetivo describir y hacer una comparación de la sobrecarga objetiva y subjetiva de la persona de la família que cuida de pacientes en el primer més de mejora y despues de tres meses de ese período . Método - Se aplicó la escala FBIS-BR en este premero més y despues de trés meses de este período. Se entrevistó 26 personas de la família de enfermos que hacian servicio de salud mental en la ciudad de Ribeirão Preto. Los datos fueron analizados a través de frecuencia y porcentaje y el test no paramétrico de Wilcoxon- test $t$ - fue aplicado para identificar los artículos de la FIBS-BR destacados en la sobrecarga de la família. Resultados y discusiónes: Las personas de la família de los 63 pacientes que asistieron las consultas fueron invitados a participar de los estúdios y de estos solamente 26 aceptaron participar. Los pacientes de esa amuestra son en la mayoría hombres, casados y tienen estúdio hacia la secundária. En relación a los que cuidan la mayoria eran mujeres y madres com um promedio de 51 años . Los participantes de ese estudio pertenecen a una baja clase social. Los diagnósticos com mayor frecuencia en el estudio fueron "esquizofrenia, trastornos esquizotípicos, trastornos delirantes y trastornos de humor". Los resultados muenstran que la sobrecarga objetiva se pone de relieve en relación a la subjetiva en los dos momentos analizados. Lo que indica que las famílias son sobrecargadas com atividades de cuidado Del enfermo, pero no se sienten perjudicados en hacer eso. Problablemente ese resultado indica que la família prefere contestar que no se molestán porque compreenden que es obligacion de ellos cuidar Del enfermo. La sobrecarga Del cuidado objetivo y subjetivo tuvieron uma disminucion del primero para el tercero més y trés aspectos pueden explicar ese resultado: Paciente aún com sintomas de la enfermedad em el primero més depues de la mejora.; 2Rehabilitación de la família depues de trés meses de la mejora.;3-Estrategia de visita en la casa por el equipo de salud. Consideraciones finales: Ese estudio apunta la importancia y necesidad de acompanãmiento de los pacientes y la família. La visita en la casa es una estrategia importante pues mantiene cerca los enfermos, la família, y el servicio de salud mental. La visita en la casa es parte de atividades Del enfermero siendo así , un de los profesionales de la equipe que puede contribuir mucho para mejorar las condiciones de enfermos y famílias.

Descriptores: Enfermería psiquiátrica, Relaciones familiares, Desinstitucionalización. 


\section{LISTA DE TABELAS}

Tabela 1 - Características sócio-demográficas e clínicas dos pacientes dispostas em freqüência e porcentagens

Tabela 2 - Características sociodemográficas dos familiares cuidadores, dispostas em freqüência e porcentagens

Tabela 3 - Médias dos escores das subescalas da FBIS-BR - Primeiro e terceiro mês

Tabela 4 - Itens da FIBS-BR, subescala A: Assistência na vida cotidiana, que apresentaram diferença estatisticamente significativa $(\mathrm{P} \leq 0,05 \quad \mathrm{P} \leq 0,01$.) entre a primeira (T0) e a terceira medida (T2) após serem submetidos ao teste de WILCOXON(- teste t-) -

Dimensão Objetiva

Tabela 5 - Itens da FIBS-BR, subescala $B$ - Supervisão de Comportamentos problemáticos, que apresentaram diferença estatisticamente significativa $(\mathrm{P} \leq 0,05 \mathrm{P} \leq 0,01$. $)$ entre a primeira (T0) e a terceira medida (T2) após serem submetidos ao teste de WILCOXON(- teste t-) -Dimensão Objetiva.

Tabela 6 - Itens da FIBS-BR, subescala $B$ - Supervisão de Comportamentos problemáticos, que apresentaram diferença estatisticamente significativa $(\mathrm{P} \leq 0,05 \mathrm{P} \leq 0,01$. $)$ entre a primeira (T0) e a terceira medida (T2) após serem submetidos ao teste de WILCOXON(- teste t-) -Dimensão Subjetiva

Tabela 7 - Itens da FIBS-BR, sub-escala $D$ - Impacto na rotina, que apresentaram diferença estatisticamente significativa $(\mathrm{P} \leq 0,05 \mathrm{P} \leq 0,01$.) entre a primeira (T0) e a terceira medida (T2) após serem submetidos ao teste de WILCOXON- teste t-. Dimensão Objetiva.. 30

Tabela 8 - Itens da FIBS-BR, sub-escala $E$ - Impacto na rotina, que apresentaram diferença estatisticamente significativa $(\mathrm{P} \leq 0,05 \mathrm{P} \leq 0,01$.) entre a primeira (T0) e a terceira medida (T2) após serem submetidos ao teste de WILCOXON- teste t-. Dimensão 


\section{SUMÁRIO}

1 - INTRODUÇÃO ......................................................................................................................11

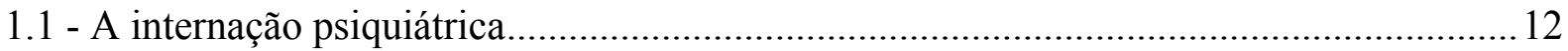

1.2 - Sobrecarga do Cuidado para o Familiar.............................................................................. 13

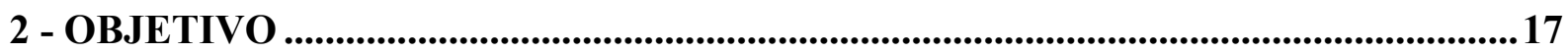

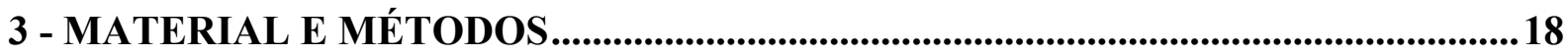

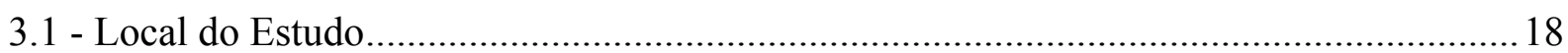

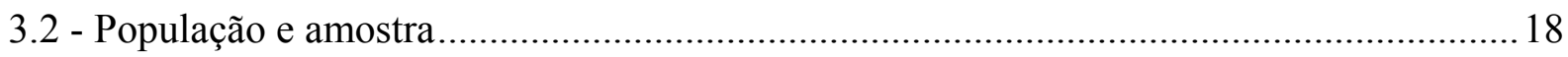

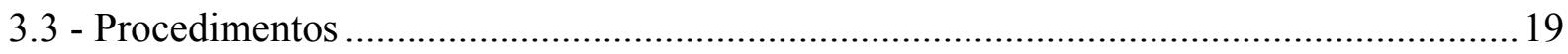

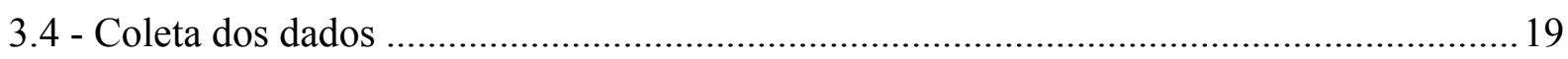

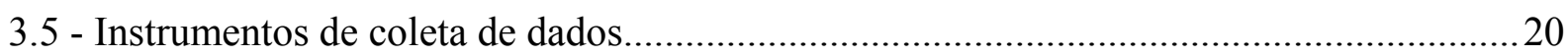

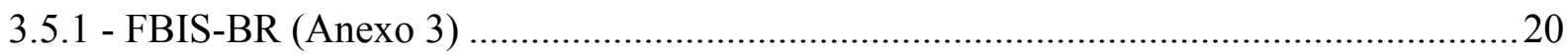

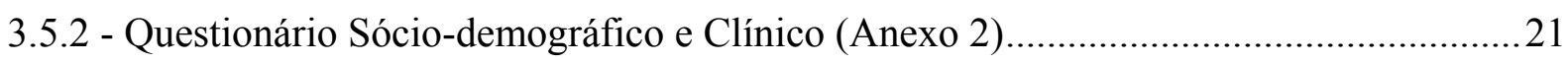

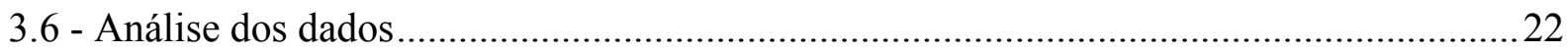

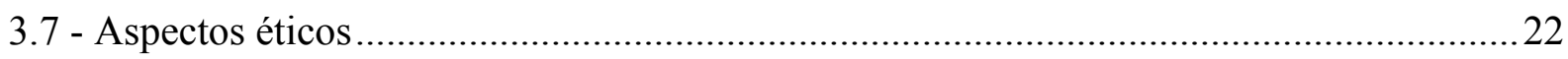

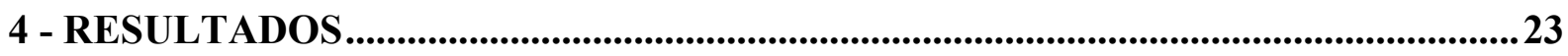

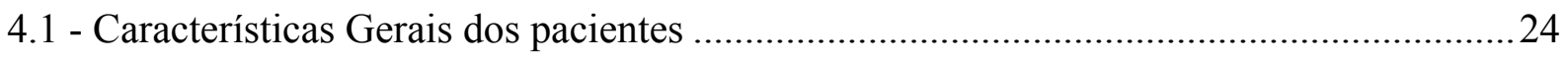

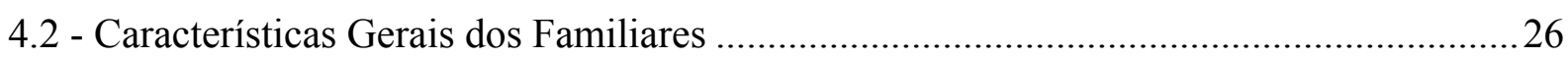

4.3 - Sobrecarga do cuidado no primeiro e terceiro mês após a alta hospitalar .......................27

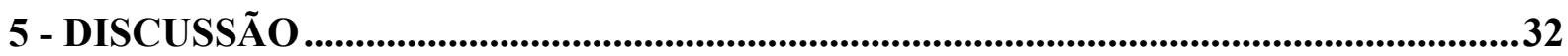

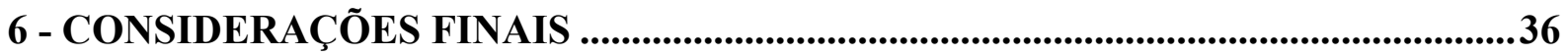

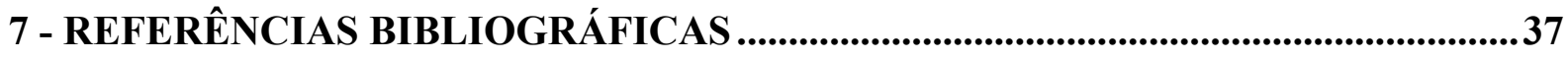

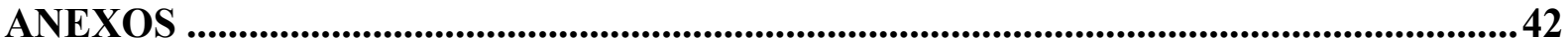

Anexo 1 - Questionário sócio-demográfico e clínico de pacientes egressos de internação

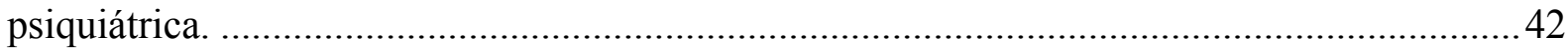

Anexo 2 - Questionário sócio-demográfico e clínico de familiares cuidadores de pacientes

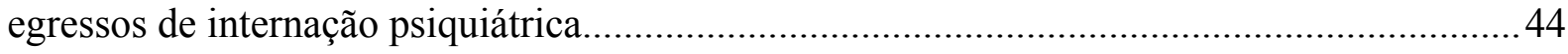

Anexo 3 - Escala de Avaliação da Sobrecarga dos familiares FBIS-BR ................................ 45

Anexo 4 - Termo de Consentimento Livre, Esclarecimento ....................................................47 


\section{1 - INTRODUÇÃO}

O processo de desinstitucionalização tornou a internação psiquiátrica mais criteriosa, com períodos mais curtos de hospitalização. A política assistencial vigente preconiza a diminuição da oferta de leitos psiquiátricos e a criação de serviços substitutivos deslocando a responsabilidade do tratamento para o interstício das dinâmicas familiares (COLVERO E ROLIM 2004). Assim, a família passou a ser a principal provedora de cuidados e apoio aos pacientes psiquiátricos (BANDEIRA E BARROSO, 2005).

A família é responsável por cuidar cotidianamente do seu familiar doente: tem de lidar com alterações de comportamento, alucinações, e delírios, déficits cognitivos, alterações de humor, estigma social associado à doença, além de acompanhar os comportamentos problemáticos, decidir se os episódios de crise necessitarão de contato com serviço de saúde mental, fornecer-lhes suporte social, arcar com seus gastos e superar as dificuldades dessas tarefas. (BANDEIRA E BARROSO, 2005, MELMAN, 2001).

O impacto do adoecimento mental sobre a família é estudado através de diversas abordagens, entre as quais estão os estudos que medem a sobrecarga do cuidado. Na década de 1990, a partir do relatório da Organização Mundial da Saúde (OMS), a medida é adotada como indicador do impacto do adoecimento mental na família. (WHO, 1992).

A sobrecarga familiar é definida como "um estado psicológico que advém da combinação de trabalho físico, emocional e pressão social, assim como a restrição econômica que emerge do cuidar de pessoa portadora de transtorno mental grave e de longa duração" (MALDONATO et. al., 2005) e engloba dois aspectos: objetivo e subjetivo.

As conseqüências concretas e observáveis resultantes da necessidade de incluir os cuidados com o doente mental no cotidiano da família caracteriza a sobrecarga objetiva. É descrita como perturbações na rotina, na vida social e profissional dos familiares, perdas financeiras, tarefas cotidianas de cuidados com o paciente, supervisão dos comportamentos problemáticos e o apoio dado ao paciente. (MAURIN E BODY, 1990).

$\mathrm{O}$ aspecto subjetivo da sobrecarga se refere à percepção ou à avaliação pessoal do familiar sobre a situação, sua reação emocional e o sentimento de sofrer uma sobrecarga, atribuída por ele à presença da doença mental na família. Refere-se ao grau com que os familiares percebem a presença de comportamentos problemáticos e a dependência dos 
pacientes como uma fonte de preocupações, sentimentos negativos e tensão psicológica. (MAURIN E BODY, 1990).

A finalidade desta pesquisa é contribuir com os estudos que avaliam a sobrecarga familiar como expressão do impacto do adoecimento mental na família. Este estudo faz parte de uma pesquisa mais ampla que tem por objetivo registrar a sobrecarga familiar em diferentes momentos da vida cotidiana, tais como na emergência psiquiátrica e no acompanhamento após a internação psiquiátrica. Esta pesquisa está inserida na coleta de dados do projeto "Sistematização da coleta de informações relevantes a manutenção do tratamento extra-hospitalar de pessoas com transtornos mentais graves" e foi direcionada para descrever a sobrecarga de cuidados do familiar em dois momentos distintos após uma internação psiquiátrica recente.

\section{1 - A internação psiquiátrica}

Pacientes com transtornos mentais graves e seus familiares vivenciam momentos cíclicos de controle e diminuição de controle sobre situações problema, as quais podem ou não resultar em recaídas e conseqüente internação psiquiátrica. Quando o processo de crises e internações se torna muito freqüente chama-se este fenômeno de porta giratória (CARDOSO, 2009).

A internação psiquiátrica tem impacto negativo nas pessoas, pois é considerada um indicador de falha no sistema de saúde, na família ou no doente. Além da sensação de fracasso que todos sentem, para o doente a internação psiquiátrica pode resultar em mais perdas no seu funcionamento global. Quanto maior o número de internações, menor é a rede social entre pacientes com esquizofrenia. (BARBOSA, G.C., 2011).

Os serviços de saúde mental, hospitalar e comunitário, têm a responsabilidade de acompanhar o doente e sua família durante e após a internação, preparando-os para retornar ao lar e conviver no seu ambiente social. Estas ações causam grande impacto na vida dos familiares. (BANDEIRA e BARROSO, 2005; MELMAN, 2001).

Fadden (1997) afirma que as intervenções com familiares durante períodos de internações psiquiátricas resultam na prevenção ou adiantamento das recaídas após a alta hospitalar. Já a não capacitação dos familiares traz o risco de diminuir de forma significativa o impacto das melhorias alcançadas na internação (FELÍCIO E ALMEIDA, 2008). 
Pesquisas recentes realizadas com pacientes com diagnóstico de esquizofrenia sugerem que o risco de recaída gira em torno de 3.5 a $10 \%$ ao mês, aproximadamente. (CSERNANSKY, et. al., 2002) Em uma revisão de estudos focada em familiares de pacientes psiquiátricos, foram apontados dados indicando que se os pacientes tiveram mais de duas internações psiquiátricas anteriormente, membros familiares destes apresentam maiores níveis de sobrecarga subjetiva, sugerindo, portanto, que o impacto aumentou com o tempo. (CARDOSO, 2008).

Para os pacientes e familiares que convivem com esse processo de internaçãoreinternação, as atividades cotidianas se organizam em torno das possibilidades de tratamento do transtorno mental, tornando a manutenção do tratamento um elemento fundamental (SALLES E BARROS, 2007; ROBINSON et al., 2007).

\section{2 - Sobrecarga do Cuidado para o Familiar}

Na Nova Zelândia foi realizado um estudo no Centro Comunitário de Saúde Mental da cidade de Auckland, com o objetivo de comparar o estresse, a sobrecarga e os sintomas mentais entre cuidadores que moram e que não moram com pacientes com diagnóstico de esquizofrenia. Foram entrevistados 85 familiares de pacientes usuários do serviço, 37 cuidadores que moravam com os seus familiares e 48 cuidadores que residiam em locais diferentes de seus familiares adoecidos. Foi utilizada a estratégia de visitas domiciliares para a aplicação dos instrumentos: Caregivers Stresso Assessment (FALLON et al., 1993) e General Health Questionnaire (GHQ). O estudo avaliou o nível de estresse em vários aspectos da vida diária e concluiu que não houve diferença significativa nos níveis de estresse entre esses dois grupos (LAIDLAW et al., 2002). Isto é, morar ou não com o doente não interfere na sobrecarga do cuidador familiar.

A sobrecarga subjetiva e objetiva foi comparada em um grupo de 70 cuidadores de pacientes com diagnóstico de esquizofrenia, que foram recrutados e entrevistados a partir de grupos de auto-ajuda $(n=57)$ e terapias particulares $(n=13)$, foram entrevistados. As escalas utilizadas nas entrevistas foram: 24 itens da escala Breaf Psychiatric Rating Scale (BPRS) para mensurar os sintomas psiquiátricos positivos e a escala Modified Scale For the Assessment of Negative Symptoms (MSANS) para os sintomas negativos dos pacientes. Para mensurar a sobrecarga de cuidado dos familiares desses pacientes, foi utilizada a escala 
Family Burden Interview Scale (FBIS). Foi realizado teste estatístico descritivo para análise dos dados. Os resultados indicaram que os sintomas negativos causam mais sobrecarga que os positivos e a severidade percebida de sintoma negativo sobre os comportamentos do pacientes foram relacionadas com a sobrecarga do cuidador objetivo. (PROVENCHER et. al., 1997). A explicação para este resultado é que os sintomas negativos incluem uma variedade de dificuldades funcionais e cognitivas que implicam em aumento de demandas para o cuidador, além de serem sintomas temporariamente estáveis em relação aos positivos que são episódicos (DYCK et. al., 1999). Os cuidadores que percebem o paciente como incapaz de alterar seus comportamentos decorrentes dos sintomas negativos e de cumprir certos papéis e obrigações, podem assumir responsabilidades extras, acarretando em maiores níveis de sobrecarga objetiva (PROVENCHER E MUESER, 1997).

Outro estudo teve como objetivo avaliar efeitos diretos e indiretos da sobrecarga familiar na adesão à medicação e no ambiente familiar. Foram entrevistados 101 pacientes e 101 cuidadores em três momentos distintos: durante a internação ou na semana de início do tratamento ambulatorial, no $7^{\circ}$ e $15^{\circ}$ mês após a primeira entrevista. As entrevistas semiestruturadas focalizavam os comportamentos problema do paciente, prejuízos no papel social do paciente e impacto da doença no tempo de trabalho, vida social e lazer dos cuidadores e ambiente familiar. Os resultados desse estudo apontam que alto nível de sobrecarga familiar está relacionado com alto nível de super envolvimento familiar, sendo que este último está ligado a um baixo nível de adesão à medicação (PERLICK et al.,2004).

$\mathrm{Na}$ Alemanha foi realizado um estudo com familiares de pacientes com diagnóstico de esquizofrenia que saíram de internação psiquiátrica. O objetivo do estudo era analisar a sobrecarga subjetiva do cuidado. A pesquisa foi realizada com 51 familiares que foram acompanhados durante 12 meses. Usando uma técnica de entrevista narrativa, os familiares foram questionados sobre a sobrecarga sofrida em decorrência da doença. As entrevistas foram realizadas em um intervalo de seis meses. Os resultados indicaram, em geral, que as mudanças no nível de sobrecarga dos pais estão intimamente interligadas com a curva de doença dos pacientes. Dos participantes do estudo, 40\% apresentaram um nível constantemente elevado de sobrecarga do cuidado durante o curso do estudo. Os resultados sugerem que os familiares de pacientes gravemente afetados estão de forma contínua afetados com uma alta carga de cuidados do cotidiano (JUNGBAUER et al., 2003).

Heru e Ryan (2004) realizaram uma pesquisa com o objetivo de avaliar a percepção de familiares em relação a sobrecarga, recompensa e funcionamento familiar de seus familiares. Foram recrutados 39 cuidadores de pacientes com diagnóstico de Transtorno Afetivo Bipolar 
(TAB) e depressão maior. Os pesquisadores coletaram os dados utilizando instrumentos para avaliar funcionamento familiar, sobrecarga subjetiva e objetiva e questionário semiestruturado para investigar as atividades diárias dos membros da família. Os resultados indicaram que os familiares de portadores de TAB apresentam maior sobrecarga e tensão quando comparados aos familiares de pessoas com depressão. No entanto, após um ano de seguimento, estas famílias obtêm uma redução da tensão, o que não acontece com os familiares de parentes depressivos. De forma geral, tanto para TAB quanto para depressão, o aspecto mais problemático no funcionamento familiar foi a comunicação.

Estudo qualitativo realizado com o objetivo de avaliar os aspectos psicossociais, financeiros e formas de enfrentamentos do cuidado em familiares de doentes mentais entrevistou 20 familiares, sendo 13 familiares de pacientes diagnosticados com esquizofrenia, 3 com depressão crônica, 3 esquizoafetivos e 3 bipolares. Todos os entrevistados relataram emoções como medo, preocupação, confusão, frustração, esperança, cuidado, simpatia, amor, tristeza, sofrimento, ressentimento. Os temas recorrentes foram: estigma relacionado ao transtorno mental, papel do cuidador, amor, cuidado e aprendizado de vida (VELTMAN E CAMERON, 2002).

Um dos poucos estudos com o objetivo de estudar a sobrecarga familiar em um país subdesenvolvido utilizou a escala Zarit Caregiver Burden Scale em 41 familiares de pacientes com diagnóstico de esquizofrenia que freqüentavam o ambulatório de saúde mental público da cidade de Arica, no Chile. Após a análise dos resultados obtidos, os autores concluíram que todos os cuidadores apresentaram um alto grau de sobrecarga, especialmente quando os cuidadores são mães, mais velhos, desempregados, quando apresentam baixo nível de escolaridade, e quando o paciente cuidado é mais jovem (URIZAR E MALDONADO, 2006).

Koga e Furegato (2002) realizaram um estudo no Brasil, com o objetivo de descrever os tipos de sobrecarga do cuidado impostas às famílias que convivem com a doença mental há mais de cinco anos. Os dados foram obtidos da análise de entrevistas semi estruturadas realizadas com 20 familiares de pacientes com diagnóstico médico de esquizofrenia inscritos no Centro Integrado de Saúde Mental (CISAM), na cidade Maringá, Paraná. Os seguintes tipos de sobrecarga foram descritos: financeiro, nas rotinas familiares e em forma de doença física ou emocional.

A sobrecarga financeira foi mencionada, pois o doente deixa de trabalhar, um ou mais familiares também deixam de trabalhar para cuidar do doente, ocorre um aumento nos gastos com medicamentos, internações, consultas e outros ônus. A sobrecarga nas rotinas foi verificada quando alguns familiares tiveram que assumir as atividades que o paciente 
realizava antes de adoecer, e muitas vezes, interromperam as suas em função do paciente. A sobrecarga em forma de doença física ou emocional revela que ao longo do tempo o cuidado com o doente mental implica em desgastes físico e mental. Foram identificaram também alterações nas atividades de lazer e nas relações sociais da família (KOGA E FUREGATO, 2002).

$\mathrm{O}$ adoecimento mental causa um profundo impacto na vida familiar. O processo de adaptação não é estático, provavelmente a família adota diferentes modos de lidar com as demandas da doença ao longo do tempo, de acordo com a própria evolução da doença, do doente e da vida familiar. Assim também a sobrecarga que o cuidado cotidiano com o doente mental impõe à família deve variar ao longo do tempo (JUNGBAUER et al., 2004).

Partindo da idéia que a família do doente metal vive um estado de sobrecarga, que varia de acordo com o estado do doente, Johannes Jungbauer et al (2003), entrevistaram 51 familiares em dois momentos diferentes na internação e após a internação e descreveram seis diferentes fases da sobrecarga: nível de sobrecarga constantemente elevado devido à função psicossocial prejudicada; sobrecarga elevada devido à deterioração causada pelos sintomas da doença; redução contínua da carga após a recaída ou episódio recente e substituição da carga.

Há estudos que apontam que a sobrecarga familiar tende a ser cíclica nos períodos críticos, parecendo, portanto, não ser estável no tempo. Assim, é provável que nos momentos de crise a sobrecarga se comporte de um jeito e nos momentos de ausência de crise se comporte de outro. ( MALDONATO et. al., 2005). 


\section{2 - OBJETIVO}

Descrever a sobrecarga do familiar cuidador de pacientes egressos de internação psiquiátrica no primeiro e no terceiro mês após a alta hospitalar. 


\section{3 - MATERIAL E MÉTODOS}

Os dados desta pesquisa foram obtidos por meio do projeto de pesquisa intitulada "Sistematização da coleta de informações relevantes a manutenção do tratamento extrahospitalar de pessoas com transtornos mentais graves" de autoria da Prof. Dra Lucilene Cardoso. Entre o conjunto de dados produzidos no projeto inicial elegemos a primeira e a terceira medida da FIBS-BR, alguns dados demográficos e clínicos do paciente e do cuidador.

\section{1 - Local do Estudo}

O estudo foi realizado no Núcleo de Saúde Mental - serviço comunitário de Saúde Mental do município de Ribeirão Preto, interior do estado de São Paulo. Trata-se de um serviço situado na região oeste desta cidade, área de abrangência da Universidade de São Paulo em termos de: atendimento à saúde, formação profissional, desenvolvimento de projetos de pesquisa e extensão, o que motivou a escolha desse serviço.

\section{2 - População e amostra}

A população do estudo é composta pelo universo de todos os pacientes residentes na região oeste de Ribeirão Preto, devidamente matriculados no NSM e seus familiares. A amostra intencional são todos os pacientes egressos de internação psiquiátrica e seus familiares que responderam as questões da FBIS-BR nos primeiros 15 dias após a alta hospitalar e em um segundo encontro após três meses. É importante enfatizar que no presente estudo apenas os familiares estão sendo avaliados.

Os critérios de inclusão foram:

- Aos pacientes: egressos de internação psiquiátrica há menos de um mês; ambos os sexos; com idade superior a 18 anos; matriculados nos serviços de saúde mental onde será realizada a coleta de dados; concordantes em participar da pesquisa. 
- Aos familiares: ambos os sexos; idade superior a 18 anos; responsável pela supervisão e administração do tratamento medicamentoso do paciente egresso; auxiliar na manutenção do tratamento psiquiátrico; que acompanhe freqüentemente a manutenção do tratamento segundo relato do paciente e referido familiar; concordantes em participar da pesquisa.

\section{3 - Procedimentos}

Recrutamento: $\mathrm{Na}$ rotina deste serviço todos os pacientes e seus familiares que passam por internação psiquiátrica são atendidos em consulta médica nos primeiros 15 dias após a alta hospitalar, para restabelecimento do seguimento assistencial extra-hospitalar. Após essa consulta médica é realizada a consulta de enfermagem, momento em que os sujeitos foram convidados a participar da pesquisa.

\section{4 - Coleta dos dados}

Para a coleta foi necessária um primeiro encontro, nos primeiros 15 dias após altahospitalar, ao qual o objetivo era identificar a situação dos sujeitos no tempo zero (T0) e encontros mensais para verificação de alterações ocorridas durante a manutenção extrahospitalar do tratamento psiquiátrico $(\mathrm{T} 1, \mathrm{~T} 2)$.

O primeiro encontro ocorreu na primeira pós consulta de enfermagem no serviço após a alta do paciente. Nesse encontro foi aplicado aos familiares/cuidadores o Questionário sobre dados sócio-demográficos e a Escala de Avaliação da Sobrecarga dos familiares FBIS-BR.

A cada trinta dias após esse encontro foram realizadas visitas domiciliares para nova coleta dos dados e verificação de oscilações na adesão ao tratamento, sobrecarga familiar, manifestação de sintomas e eventos cotidianos estressores ao familiar cuidador. As visitas foram agendadas e realizadas entrevistas em local reservado a cada sujeito para preenchimento dos instrumentos para evitar possíveis constrangimentos entre os familiares. Nos casos em que os sujeitos não aceitaram ser visitados em domicílio foi realizada a coleta no serviço de saúde. 


\section{5 - Instrumentos de coleta de dados}

Os dados foram coletados através dos seguintes instrumentos: Questionário sóciodemográfico e clínico de pacientes egressos de internação psiquiátrica (Anexo 1), Questionário sócio-demográfico e clínico de familiares cuidadores de pacientes egressos de internação psiquiátrica (Anexo 2) e Escala de Avaliação da Sobrecarga dos familiares FBIS-BR (Anexo 3)

\subsection{1 - FBIS-BR (Anexo 3)}

A escala original (FBIS/SF), elaborada por Tessler e Gamache em 1994, é uma escala multifatorial de língua inglesa que avalia a sobrecarga familiar, a partir de cinco sub-escalas, correspondentes a cinco dimensões da vida do familiar que se referem aos trinta dias anteriores à data da entrevista (BANDEIRA 1991). A versão brasileira foi adaptada transculturalmente para o Brasil por Bandeira, Calzavara e Varella em 2005 e apresentou boas propriedades psicométricas de estabilidade temporal e consistência interna, sendo, portanto, um instrumento confiável (BANDEIRA, 1991;PLAYLE ,1998; KECK,1996).

A escala fornece escores independentes para a sobrecarga objetiva e subjetiva e, por avaliar diversas dimensões separadamente, permite que conheçamos as áreas de maior ou menor sobrecarga sentida pelo familiar, na promoção do cuidado (BANDEIRA, 1991).

A escala FBIS-BR possui 70 questões, dentre as quais 45 se referem ao grau de sobrecarga, sendo 21 itens de sobrecarga objetiva e 24 itens de sobrecarga subjetiva.

A escala avalia o grau de sobrecarga dos familiares em cinco dimensões da vida dos familiares, que consistem nas seguintes cinco subescalas: 1. assistência na vida cotidiana do paciente; 2. supervisão aos comportamentos problemáticos do paciente; 3. gastos financeiros do familiar com o paciente; 4. impacto nas rotinas diárias da família; 5. preocupação do familiar com o paciente.

A sobrecarga objetiva é avaliada por meio da freqüência em que o familiar prestou assistência ao paciente nas tarefas cotidianas (subescala A), teve que lidar e supervisionar os seus comportamentos problemáticos (subescala B) e sofreu alterações em sua vida profissional e social (subescala D) com o seu papel de cuidador. Esta freqüência é avaliada em uma escala de 5 pontos, onde: $1=$ nenhuma vez; $2=$ menos que uma vez por semana; $3=$ uma ou duas vezes por semana; $4=$ de três a seis vezes por semana; $5=$ todos os dias. 
A sobrecarga subjetiva é avaliada pelo grau de incômodo sentido pelo familiar ao prestar assistência cotidiana ao paciente (subescala A) e ao lidar com seus comportamentos problemáticos (subescala B), assim como pelo sentimento do familiar de estar carregando um peso financeiro (uma questão da sub-escala $C$ ) e pela freqüência de suas preocupações com o paciente (subescala E). Para a avaliação do grau de incômodo, as opções de resposta são: 1= nem um pouco; $2=$ muito pouco; $3=$ um pouco; 4= muito (SCAFUZA, 2002).

Dos itens que compõe a escala quatro não podem ser utilizados no cálculo dos escores de sobrecarga por terem apresentado valores baixos de fidedignidade $(r<0,20$ item-total), no estudo de validação. Provavelmente isso ocorreu devido ao estudo encontrar baixa freqüência desses problemas na amostra. São eles os de número 6 e 8 da sub-escala B objetiva e os itens 6 e 8 da sub-escala $B$ subjetiva que se referem à ajuda que o familiar prestou ao paciente ao ter que lidar com comportamentos problemáticos relacionados ao abuso de álcool e de drogas.

Além desses itens, não foram contabilizados nos escores da sobrecarga: A sub-escala C (por tratarem de valores em dinheiro das despesas e da contribuição do paciente), os itens dentro da subescala D que avaliam as mudanças permanentes ocorridas na vida do familiar (uma vez que todos os escores que são incluídos nos cálculos de sobrecarga envolvem questões que se referem apenas aos últimos 30 dias) e o item final (referente à freqüência com que o familiar considerou que eram pesados os gastos que ele teve com o paciente). (DROULOUT et. al., 2003)

No entanto, por serem itens importantes para aprofundar o conhecimento dos pesquisadores, conforme sugestão dos autores do trabalho de validação, todos os itens foram mantidos nas aplicações da escala, embora não utilizados para contabilizar os escores da sobrecarga.

Desta maneira, a escala totaliza 41 itens quantitativos que devem ser incluídos nos cálculos dos escores de sobrecarga, sendo 19 de sobrecarga objetiva e 22 de sobrecarga subjetiva. O tempo de aplicação da escala dura aproximadamente 40 minutos.

\subsection{2 - Questionário Sócio-demográfico e Clínico (Anexo 2)}

O questionário é um conjunto de questões pré-elaborado, e seqüencialmente disposto em itens que contextualizam o tema da pesquisa. Foi elaborado pela pesquisadora e contempla as seguintes variáveis: 


\section{Cuidador}

Vínculo familiar com o paciente; Sexo; Idade; Procedência; Com quem mora; Estado civil; Número de filhos; Escolaridade; Situação ocupacional; Renda pessoal; Renda familiar; Quem mais do grupo familiar auxilia nos cuidados com o paciente.

\section{Paciente-}

Diagnóstico e número de internações, Sexo; Idade; Procedência; Com quem mora; Estado civil; Número de filhos; Escolaridade; Situação ocupacional; Renda pessoal; Renda familiar; Hipótese Diagnóstica (de acordo com o CID-10); Tempo de manifestação do transtorno psiquiátrico; número de internações; Data da última internação; local do tratamento.

\section{6 - Análise dos dados}

Ao considerar os dados referentes a identificação dos pacientes egressos e seus familiares utilizamos a estatística descritiva. Foi aplicado o teste que verificava se a escala utilizada (FBIS-BR), identifica as mudanças da sobrecarga do cuidado ao longo do tempo (três meses). O teste estatístico de WILCOXON -teste T- é uma prova não paramétrica que foi utilizada para comparar os dados das entrevistas TO (primeiro mês) e T2 (terceiro mês).

\section{7 - Aspectos éticos}

O projeto de pesquisa que originou os dados desta dissertação, intitulado "Sistematização da coleta de informações relevantes a manutenção do tratamento extrahospitalar de pessoas com transtornos mentais graves" foi submetido à autorização do Comitê de Ética e Pesquisa do CSE-FMRP-USP responsável pelo serviço de saúde local de coleta desta pesquisa e aprovado em 23 de junho de 2009, sob protocolo no. 320/CEP-CSEFMRP-USP, atendendo à Resolução 196/96. Todos os sujeitos da pesquisa receberam esclarecimento quanto ao objetivo do estudo e procedimentos e assinaram o Termo de Consentimento Livre e Esclarecido ou em qualquer fase do estudo (TCLE Anexo 4 ). 


\section{4 - RESULTADOS}

Durante seis meses foram agendadas 80 consultas médicas a pacientes egressos de internação psiquiátrica. No total, 63 pessoas compareceram. Após o atendimento, todos os familiares presentes foram convidados a participar da pesquisa. Os resultados apresentados a seguir, portanto, referem-se aos familiares de egressos de internação psiquiátrica que aceitaram responder ao questionário, ao todo, 26 pessoas. 


\section{1 - Características Gerais dos pacientes}

Tabela 1 - Características sócio-demográficas e clínicas dos pacientes dispostas em freqüência e porcentagens

\begin{tabular}{|c|c|c|}
\hline Variáveis & & Freqüência $\mathbf{N}(\%)$ \\
\hline \multirow{2}{*}{ Sexo } & Feminino & $10(38,5)$ \\
\hline & Masculino & $16(61,5)$ \\
\hline \multirow{2}{*}{ Idade } & Entre 22 e 42 & $14(46,2)$ \\
\hline & Entre 43 e 68 & $12(44,8)$ \\
\hline \multirow{4}{*}{ Estado Civil } & Casado ou amasiado & $11(42,3)$ \\
\hline & Nunca se casou & $8 \quad(30,8)$ \\
\hline & Separado & $2(7,7)$ \\
\hline & Viúvo & $2(7,7)$ \\
\hline \multirow{4}{*}{ Filhos } & Não Tem & $8 \quad(30,8)$ \\
\hline & Tem 1 filho & $3(11,5)$ \\
\hline & Tem 2 filhos & $9(34,6)$ \\
\hline & Tem 3 filhos ou mais & $6 \quad(23,1)$ \\
\hline \multirow{6}{*}{ Escolaridade } & Analfabeto & $2(7,7)$ \\
\hline & $1^{\circ}$ grau incompleto & $12(46,2)$ \\
\hline & $1^{\circ}$ grau completo & $4(15,4)$ \\
\hline & $2^{\circ}$ grau incompleto & $4(15,4)$ \\
\hline & $2^{\circ}$ grau completo & $2(7,7)$ \\
\hline & $3^{\circ}$ grau incompleto & $2(7,7)$ \\
\hline \multirow{7}{*}{ Trabalho } & Afastado & $9(34,6)$ \\
\hline & Nunca Trabalhou & $6(23,1)$ \\
\hline & Faz trabalhos irregulares "bicos" & $4(15,4)$ \\
\hline & Desempregado & $3(11,5)$ \\
\hline & Trabalho regular informal & $2(7,7)$ \\
\hline & Trabalho regular registrado & $1(3,8)$ \\
\hline & Aposentado pelo INSS & $1(3,8)$ \\
\hline \multirow{2}{*}{ Com quem o paciente mora } & Com familiares & $25(96,2)$ \\
\hline & Com amigos & $1(3,8)$ \\
\hline \multirow{3}{*}{ Situação da casa } & Própria & $21(80,8)$ \\
\hline & Alugada & $4(15,4)$ \\
\hline & Cedida ou emprestada & $1 \quad(3,8)$ \\
\hline \multirow{4}{*}{ Principais Diagnósticos } & F20 a F29 & $10(38,5)$ \\
\hline & F30 a F39 & $7 \quad(26,9)$ \\
\hline & F60 a F69 & $1 \quad(3,8)$ \\
\hline & Mais de um diagnóstico & $8 \quad(30,8)$ \\
\hline \multirow{4}{*}{ Tempo de Doença } & 1 ano & $3(11,5)$ \\
\hline & 2 anos & $1 \quad(3,8)$ \\
\hline & 5 anos ou mais & $17(65,4)$ \\
\hline & Não soube dizer & $5 \quad(19,2)$ \\
\hline \multirow{5}{*}{ Internações } & Primeira & $8(30,8)$ \\
\hline & Segunda & $4(15,4)$ \\
\hline & Terceira & $3(11,5)$ \\
\hline & Quarta & $2(7,7)$ \\
\hline & 10 ou mais internações & $8(30,8)$ \\
\hline \multirow{3}{*}{ Local Ultima Internação } & H. Sta Tereza & $18(69,2)$ \\
\hline & HCFMRP / U E & $4(15,4)$ \\
\hline & Outros & $4(15,4)$ \\
\hline
\end{tabular}

$(\mathrm{N}=26$, sendo $\mathrm{N}=$ número absoluto dos pacientes pesquisados) Ribeirão Preto, 2011 
Foram entrevistados 26 pacientes egressos de internação psiquiátrica: 16 homens e 10 mulheres, com média de idade de 41 anos, sendo que o mais jovem tem 22 e o mais velho 68 anos. A maioria (42\%) está casada, possui baixa escolaridade e encontra-se afastada do trabalho ou nunca trabalhou. Apenas um dos pacientes não residia com familiares, mas com amigos.

Com relação ao diagnóstico médico, feito de acordo com o CID-10 (Classificação Internacional da Doenças), observou-se que a maioria dos participantes são diagnosticados nos seguintes agrupamentos: Esquizofrenia, Transtornos Esquizotípicos e Delirantes (38,5\%) e Transtornos de Humor (26,9\%). Com mais de um diagnóstico encontram-se oito pacientes, ou seja, $30,8 \%$, sendo que destes, sete têm o Transtorno de Personalidade como um dos seus principais diagnósticos.

Em relação ao tempo aproximado da manifestação do transtorno psiquiátrico nos pacientes, constatou-se que: $65,4 \%$ deles foram diagnosticados há cinco anos ou mais e 19,2\% não souberam responder. Dos 26 pacientes entrevistados, oito estavam em sua primeira internação e nove tinham menos de cinco internações psiquiátricas. A última internação de 69,2\% destes pacientes foi no Hospital Santa Tereza, de 15,4\% no HCFMRP/UE e dos outros $15,4 \%$, em outros locais, como hospitais psiquiátricos particulares da região. 


\section{2 - Características Gerais dos Familiares}

Tabela 2 - Características sociodemográficas dos familiares cuidadores, dispostas em freqüência e porcentagens

\begin{tabular}{|c|c|c|}
\hline Variáveis & & Freqüência N(\%) \\
\hline \multirow{2}{*}{ Sexo } & Feminino & $16(61,5)$ \\
\hline & Masculino & $10(38,5)$ \\
\hline \multirow{7}{*}{ Parentesco } & Mãe & $11(42,3)$ \\
\hline & Esposo (a) & $5(19,2)$ \\
\hline & Irmão ou irmã & $4(15,4)$ \\
\hline & Pai & $3(11,5)$ \\
\hline & Filho ou filha & $1(3,8)$ \\
\hline & Tio & $1(3,8)$ \\
\hline & Outros & $1(3,8)$ \\
\hline \multirow{2}{*}{ Idade } & Entre 35 e 71 & $23(88,4)$ \\
\hline & Entre 18 e 34 & $3(12,6)$ \\
\hline \multirow{5}{*}{ Estado Civil } & Casado ou amasiado & $18(69,2)$ \\
\hline & Viúvo & $6(23,1)$ \\
\hline & Separado & $3(9,1)$ \\
\hline & Nunca se casou & $1(3,8)$ \\
\hline & Divorciado & $1(3,8)$ \\
\hline \multirow{4}{*}{ Filhos } & Tem 3 filhos ou mais & $11(42,3)$ \\
\hline & Tem 2 filhos & $7(26,9)$ \\
\hline & Tem 1 filho & $4(15,4)$ \\
\hline & Não tem & $3(11,5)$ \\
\hline \multirow{5}{*}{ Escolaridade } & $1^{\circ}$ grau incompleto & $14(53,8)$ \\
\hline & Analfabeto & $4(15,4)$ \\
\hline & $1^{\circ}$ grau completo & $3(11,5)$ \\
\hline & $2^{\circ}$ grau completo & $3(11,5)$ \\
\hline & $2^{\mathrm{o}}$ grau incompleto & $2(7,7)$ \\
\hline \multirow{6}{*}{ Trabalho } & Faz"bicos" & $10(30,3)$ \\
\hline & Trabalho regular e informal & $5(19,2)$ \\
\hline & Trabalho regular e registrado & $3(11,5)$ \\
\hline & Aposentados & $2(7,7)$ \\
\hline & Nunca trabalhou & $2(7,7)$ \\
\hline & Desempregado & $1(3,8)$ \\
\hline
\end{tabular}

A maioria dos cuidadores são mulheres $(61,5 \%)$ e mães $(42,3 \%)$. A média de idade é de 51 anos, sendo que o mais jovem tem 18 anos e o mais velho, 71. Dos entrevistados, $69,2 \%$ são casados ou amasiados e metade, $53 \%$, não completou o primeiro grau. Quanto ao trabalho, a maioria $(30,3 \%)$ realiza "bicos", isto é, trabalhos temporários. 


\section{3 - Sobrecarga do cuidado no primeiro e terceiro mês após a alta hospitalar}

A Tabela 3 descreve os escores médios das respostas dos familiares e as subescalas da FBIS-BR na primeira (T0) e na terceira entrevista (T2). Observa-se que em todos os itens das subescalas houve decréscimo das médias entre as duas medidas, demonstrando uma diminuição da sobrecarga do cuidado da primeira entrevista para a terceira. A sobrecarga objetiva se refere às conseqüências concretas e observáveis resultantes do cuidado com o doente mental na família. Nesta pesquisa, o escore objetivo global no primeiro mês após a internação psiquiátrica foi de 2,20 e no terceiro mês de 1,91. A diferença do escore global de sobrecarga objetiva da primeira medida para a terceira foi de 0,19 .

$\mathrm{O}$ aspecto subjetivo da sobrecarga se refere à percepção ou à avaliação pessoal do familiar sobre a situação; sua reação emocional e ao sentimento de sofrer uma sobrecarga atribuída por ele à presença da doença mental na família. $\mathrm{O}$ escore subjetivo global no primeiro mês após a internação psiquiátrica foi de 2,51 e no terceiro mês, de 2,17. A diferença do escore global da sobrecarga subjetiva da primeira medida para a terceira medida foi de 0,34 .

Observa-se que as dimensões das sobrecargas objetivas são maiores em relação as das sobrecargas subjetivas em todos os itens, exceto no item E - Preocupação com o paciente, que apresenta escore médio elevado na primeira e terceira medidas.

Tabela 3 - Médias dos escores das subescalas da FBIS-BR - Primeiro e terceiro mês.

\begin{tabular}{|l|c|c|c|}
\hline Subescalas & $\begin{array}{c}\text { Dimensões da } \\
\text { Sobrecarga }\end{array}$ & $\begin{array}{c}\text { Médias } \\
\text { Primeiro } \\
\text { Mês (T0) }\end{array}$ & $\begin{array}{c}\text { Médias } \\
\text { Terceiro } \\
\text { Mês (T2) }\end{array}$ \\
\hline A - Assistência na vida Cotidiana & Objetiva & 2,66 & 2,35 \\
& Subjetiva & 2,09 & 1,73 \\
\hline B - Supervisão de Comportamentos & Objetiva & 1,84 & 1,49 \\
problemáticos & Subjetiva & 1,78 & 1,47 \\
\hline D - Impacto na rotina & Objetiva & 2,11 & 1,89 \\
\hline E - Preocupações com o paciente & Subjetiva & 3,66 & 3,32 \\
\hline Escore Global Objetivo & & $\mathbf{2 , 2 0}$ & $\mathbf{1 , 9 1}$ \\
\hline Escore Global Subjetivo & & $\mathbf{2 , 5 1}$ & $\mathbf{2 , 1 7}$ \\
\hline
\end{tabular}

$(\mathrm{N}=26$, sendo $\mathrm{N}=$ numero absoluto dos pacientes pesquisados) Ribeirão Preto, 2011. 
Foi aplicado o teste estatístico não-paramétrico de WILCOXON-teste $t$ - para a identificação dos itens da FBIS-BR que apresentaram diferença estatisticamente significativa $(\mathrm{P} \leq 0,05 \mathrm{P} \leq 0,01$.) da primeira (T0) para a terceira medida (T3). Os itens identificados foram apresentados nas tabelas que se seguem (Tabela 4 a 8) e descrevem cada subescala (subescala): A: Assistência na vida Cotidiana (Tabela 4); B: Supervisão de Comportamentos problemáticos, dimensao obetiva (Tabela 5); B: Supervisão de Comportamentos problemáticos, dimensao subjetiva (Tabela 7), D: Impacto na rotina (Tabela 6), E: Preocupações com o paciente (Tabela 8).

Tabela 4 - Itens da FIBS-BR, subescala A: Assistência na vida cotidiana, que apresentaram diferença estatisticamente significativa $(P \leq 0,05 \quad P \leq 0,01$.) entre a primeira (T0) e a terceira medida (T2) após serem submetidos ao teste de WILCOXON(- teste t-) Dimensão Objetiva

\begin{tabular}{|c|c|c|c|c|c|}
\hline \multirow[t]{2}{*}{$\begin{array}{l}\text { A: } \\
\text { Assistência na vida } \\
\text { cotidiana }\end{array}$} & \multicolumn{2}{|c|}{ Resposta 1 e Resposta 2} & \multicolumn{2}{|c|}{ Resposta 4 e Resposta 5} & \multirow[t]{2}{*}{$\begin{array}{c}\text { Teste } t \\
\text { (Diferença } \\
\text { significativa) }\end{array}$} \\
\hline & $\begin{array}{c}\text { T0 } \\
\text { Primeiro mês }\end{array}$ & $\begin{array}{c}\text { T2 } \\
\text { Terceiro mês }\end{array}$ & $\begin{array}{c}\text { T0 } \\
\text { Primeiro mês }\end{array}$ & $\begin{array}{c}\text { T2 } \\
\text { Terceiro mês }\end{array}$ & \\
\hline A2- Medicação & $12(46,1)$ & $14(53,8)$ & $14(53,8)$ & $10(38,5)$ &, 007 \\
\hline A5-Alimentação & $12(46,1)$ & $14(53.9)$ & $13(50,0)$ & $9(34,6)$ &, 005 \\
\hline A6-Transporte & $14(53.9)$ & $15(53,7)$ & $8(30,8)$ & $6(23,0)$ & ,090 \\
\hline A9-Consultas médicas & $11(42,3)$ & $15(57,6)$ & $13(50,0)$ & $9(34,6)$ & 011 \\
\hline
\end{tabular}

Na subescala A- Assistência da vida cotidiana, a sobrecarga objetiva é avaliada por meio da freqüência em que o familiar prestou assistência ao paciente nas tarefas cotidianas. $\mathrm{O}$ escore médio objetivo da primeira entrevista foi de 2,66 e no terceiro mês de 2,35. Administração dos medicamentos, Preparo de Alimentos, Transporte e Freqüência as consultas médicas e trabalho foram os itens da escala FBIS-BR que obtiveram diferença estatisticamente significativa entre o primeiro e o terceiro mês após a alta hospitalar. Isto é, no primeiro mês a supervisão quanto: medicamentos, o preparar das refeições, o transporte e acompanhamento do paciente a consultas por parte do cuidador, aconteciam com mais freqüência no primeiro mês e geravam assim, uma sobrecarga maior.

Em relação a sobrecarga subjetiva, os itens da subescala A não obtiveram diferença estatisticamente significativa entre a primeira e a terceira entrevista. 
Tabela 5 - Itens da FIBS-BR, subescala B - Supervisão de Comportamentos problemáticos, que apresentaram diferença estatisticamente significativa $(\mathrm{P} \leq \mathbf{0 , 0 5}$ $\mathbf{P} \leq \mathbf{0 , 0 1}$.) entre a primeira (T0) e a terceira medida (T2) após serem submetidos ao teste de WILCOXON(- teste t-) - Dimensão Objetiva

B:

Supervisão de

Comportamentos

Resposta 1 e Resposta $2 \quad$ Resposta 4 e Resposta 5

Teste $\mathbf{t}$

Problemáticos

Objetiva

T0

Primeiro mês

T2

Terceiro mês

T0

Primeiro mês

T2

Terceiro mês

B3-Perturbação

Noturna

$20(76,9)$

$21(80,8)$

$2(7,6)$

$2(7,6)$

,066

B6-Bebidas

Alcoólicas

$22(84,6)$

$24(92,3)$

$3(3,8)$

0

, 006

B7-Excesso de

alimentos, cigarro

20(76,9)

24(92,3)

$4(15,4)$

0

, 087

e líquidos

B8-Abuso de

Drogas

$23(88,5)$

25(96,2)

$1(3,8)$

0

, 000

$\mathrm{P} \leq 0,05$ ou $\mathrm{P} \leq 0,011=$ nenhuma vez; $2=$ menos que uma vez por semana; $3=$ uma ou duas vezes por semana; $4=$ de três $a$ seis vezes por semana; $5=$ todos os dias. $(\mathrm{N}=26$, sendo $\mathrm{N}=$ numero absoluto dos pacientes pesquisados) Ribeirão Preto 2011 .

Tabela 6 - Itens da FIBS-BR, subescala B - Supervisão de Comportamentos problemáticos, que apresentaram diferença estatisticamente significativa $(\mathrm{P} \leq 0,05$ $\mathrm{P} \leq 0,01$.) entre a primeira (T0) e a terceira medida (T2) após serem submetidos ao teste de WILCOXON(- teste t-) - Dimensão Subjetiva.

\begin{tabular}{|c|c|c|c|c|c|}
\hline $\begin{array}{l}\text { B: } \\
\text { Supervisão de } \\
\text { Comportamentos } \\
\text { Problemáticos } \\
\end{array}$ & Resposta 1 & Resposta 2 & Resposta 3 & Resposta 4 & $\begin{array}{c}\text { Teste t } \\
\text { (Diferença } \\
\text { significativa) }\end{array}$ \\
\hline Subjetiva & $\begin{array}{c}\text { T0 } \\
\text { Primeiro mês }\end{array}$ & $\begin{array}{c}\text { T2 } \\
\text { Terceiro mês }\end{array}$ & $\begin{array}{c}\text { T0 } \\
\text { Primeiro mês }\end{array}$ & $\begin{array}{c}\text { T2 } \\
\text { Terceiro mês }\end{array}$ & \\
\hline $\begin{array}{l}\text { B3-Perturbação } \\
\text { Noturna }\end{array}$ & $19(73,1)$ & $22(84,6)$ & $1(3,8)$ & $2(7,7)$ &, 035 \\
\hline $\begin{array}{l}\text { B6-Bebidas } \\
\text { Alcoólicas }\end{array}$ & $22(4,6)$ & $24(92,3)$ & $4(15,3)$ & $1(3,8)$ & ,013 \\
\hline $\begin{array}{l}\text { B7-Excesso de } \\
\text { alimentos, cigarro } \\
\text { e líquidos }\end{array}$ & $20(76,9)$ & $24(92,3)$ & $4(15,3)$ & $2(7,7)$ & ,098 \\
\hline $\begin{array}{l}\text { B8-Abuso de } \\
\text { Drogas }\end{array}$ & $23(88,5)$ & $25(96,2)$ & $3(11,5)$ & 0 &, 002 \\
\hline
\end{tabular}


Considerando a supervisão dos comportamentos problemáticos subescala B destaca-se que os mesmos itens da sobrecarga objetiva e subjetiva apresentaram diferença estatisticamente significativa. $O$ teste $t$ indicou diminuição da sobrecarga objetiva e subjetiva nas respostas do primeiro mês para o terceiro nos seguintes itens: Perturbação durante a noite, supervisionar Bebidas alcoólicas, Excesso de alimentos,cigarros e líquidos e Abuso de drogas. Com isso, observa-se que no primeiro mês apos a alta hospitalar a supervisão dos familiares a esses comportamentos geravam sobrecarga objetiva e subjetiva ao familiar significativamente alta, e com o passar de três meses ouve uma diminuição desta carga de cuidados.

Tabela 7 - Itens da FIBS-BR, sub-escala $D$ - Impacto na rotina, que apresentaram diferença estatisticamente significativa $(P \leq 0,05 \quad P \leq 0,01$.) entre a primeira (T0) e a terceira medida (T2) após serem submetidos ao teste de WILCOXON- teste t-. Dimensão Objetiva.

\begin{tabular}{|c|c|c|c|c|c|}
\hline \multirow{2}{*}{$\begin{array}{l}\text { D: } \\
\text { Impacto na rotina }\end{array}$} & \multicolumn{2}{|c|}{ Resposta 1 e Resposta 2} & \multicolumn{2}{|c|}{ Resposta 4 e Resposta 5} & \multirow{2}{*}{$\begin{array}{c}\mathbf{P} \\
\text { (Diferença } \\
\text { significativa) }\end{array}$} \\
\hline & $\begin{array}{c}\text { T0 } \\
\text { Primeiro mês }\end{array}$ & $\begin{array}{c}\text { T2 } \\
\text { Terceiro mês }\end{array}$ & $\begin{array}{c}\text { T0 } \\
\text { Primeiro mês }\end{array}$ & $\begin{array}{c}\text { T2 } \\
\text { Terceiro mês }\end{array}$ & \\
\hline $\begin{array}{l}\text { D2 - Impacto } \\
\text { permanente na } \\
\text { vida do cuidador }\end{array}$ & $9(34,6)$ & $11(42,3)$ & $10(38,9)$ & $4(15,3)$ &, 002 \\
\hline
\end{tabular}

O impacto na rotina do familiar imposta pelo cuidado com o paciente psiquiátrico é avaliado na subescala D da FBIS-BR. Esta subescala é avaliada somente no aspecto objetivo e obteve escore médio de 2,11 na primeira entrevista e 1,89 na terceira entrevista. $O$ item da subescala D que apresentou diferença estatisticamente significativa entre a primeira entrevista e a terceira foi o Impacto permanente na vida do cuidador, o que demonstra que esta sobrecarga objetiva diminuiu após três meses no convívio do familiar com o doente. 
Tabela 8 - Itens da FIBS-BR, sub-escala $E$ - Impacto na rotina, que apresentaram diferença estatisticamente significativa $(P \leq 0,05 \quad P \leq 0,01$.) entre a primeira (T0) e a terceira medida (T2) após serem submetidos ao teste de WILCOXON- teste t-. Dimensão Subjetiva

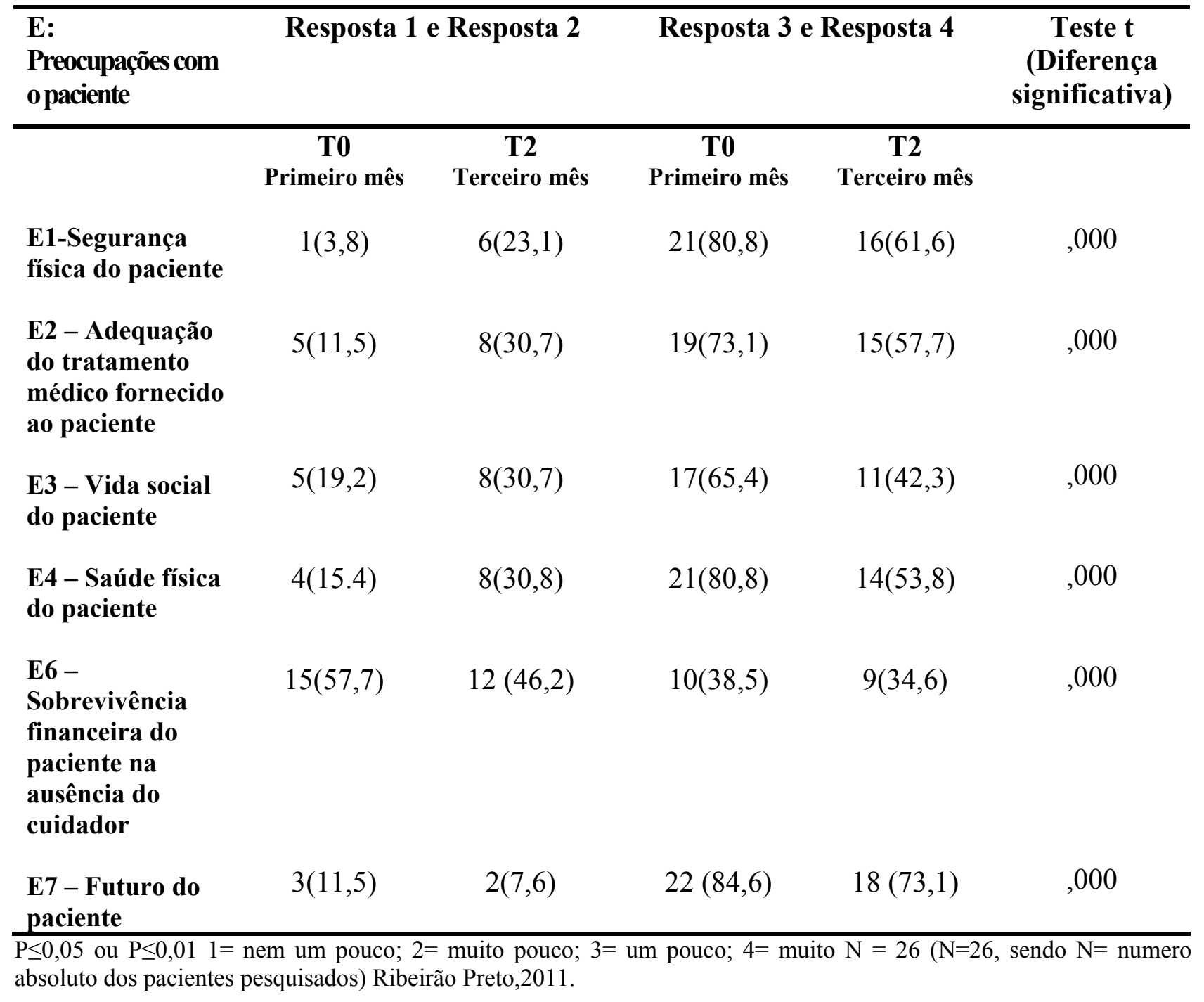

A preocupação com o paciente apresentou escore médio no primeiro mês de 3,66 e no terceiro mês de alta hospitalar de 3,32. Esta é a subescala que indica maiores escores médios e foi a que mais apresentou itens estatisticamente significativos para a sobrecarga familiar. De todos os seus itens, apenas o item E5-Condições de moradia do paciente não indicou sobrecarga estatisticamente significativa. Assim, como as demais subescalas, a sobrecarga subjetiva apresentou decréscimo da primeira para a terceira medida. Ao declarem no primeiro momento que a preocupação é alta com o futuro de seu familiar doente, observa-se que o paciente é mais dependente de cuidado logo após o primeiro mês de alta hospitalar do que após três meses deste período. 


\section{5 - DISCUSSÃO}

Durante o período de seis meses o serviço de saúde recebeu 80 pacientes egressos de internação psiquiátrica, porém somente 63 compareceram. É importante destacar que no primeiro mês após a internação psiquiátrica 17 pacientes não deram continuidade no tratamento. Os familiares dos 63 pacientes foram convidados a participar do presente estudos e destes somente 26 aceitaram participar da pesquisa. Assim como em outra pesquisa no mesmo local alguns familiares alegaram não quererem participar por exercerem algum trabalho regular e com isso não teriam horário disponível. (CARDOSO, 2009).

A família é um núcleo cotidiano de convívio social, rico em perspectivas e necessidades que também precisa ser trabalhada e assistida pelos serviços de saúde mental na promoção à saúde. Devido à natureza crônica da doença mental, a família e em especial o familiar/cuidador é submetido a constantes eventos estressores no curso destas doenças. $\mathrm{O}$ que pode afetar além das relações familiares a saúde do próprio familiar/cuidador (MELLO, 2005). Assim como observado em outros estudos a maioria dos cuidadores participantes desta pesquisa são mulheres $(61,5 \%)$ e mães $(42,3 \%)$. Este resultado tem sido explicado na literatura através do papel cultural das mulheres, especialmente mães, responsáveis pelo cuidado dos membros da família. (SILVA, SANTOS, 2009). Duarte et al. (2007) salientam que este dado merece ser estudado pela enfermagem, destacando que o referencial feminista poderá ser bastante útil.

O grau de escolaridade dos cuidadores desta amostra assim como dos pacientes, foi baixo, a maioria deles não completaram o primeiro grau, não tem fonte de renda fixa, realizam trabalhos temporários "bicos". A baixa escolaridade, assim como a falta de trabalho remunerado do doente como de seu familiar indicam que nossa amostra é constituída por uma faixa da população de baixa renda, embora a maioria têm casa própria $(80,8 \%)$. É importante lembrar que o serviço publico de saúde mental no Brasil atende principalmente a população de baixa renda. (ZANETTI, A.C.G., 2010).

O presente trabalho identificou que os egressos de internação psiquiátrica nesta amostra são homens $(61,5 \%)$, casados (46,2\%). Amarante, et. al. no ano de 1999 realizou um estudo no estados do Rio de Janeiro que caracteriza o perfil dos pacientes de internações psiquiátricas, e seus resultados apontam que a maioria e homem, com baixa escolaridade porém solteiros. 
Umas das conseqüências da Reforma Psiquiátrica é que o doente fica sob a responsabilidade da família. Neste estudo a maioria $(96,2 \%)$ dos doentes vivem com suas famílias. A família torna-se uma das protagonistas, juntamente com os serviços substitutivos, provedores principais dos cuidados ao paciente no ambiente extra-hospitalar. (COLVERO; IDE; ROLIM, 2004; PEJLERT, 2001; DUARTE et. al., 2007).

Os egressos de internação psiquiátrica entrevistados não trabalhavam e poucos tinham alguma fonte de renda. Esses dados são semelhantes a outros estudos realizados com pacientes avaliados em serviços de atendimento comunitário. (MATINEZ, A, 2000; DOORNBOS, M.M., 1997). A inclusão no processo de produção da vida material pelo trabalho é um aspecto fundamental das relações sociais. (ARANHA E SILVA et. al., 2005). A falta da realização de um trabalho pode deixar os pacientes mais dependentes de seus familiares cuidadores.

Os diagnósticos mais prevalentes no estudo foram dos seguintes agrupamentos: "Esquizofrenia, transtornos esquizotípicos, Transtornos delirantes e Transtornos de Humor". Outros estudos sobre egressos de internação psiquiátrica também encontraram esses diagnósticos como mais freqüência (COUTINHO et al 2002, ALMEIDA, 1999). Estes transtornos graves e crônicos limitam a vida social e pessoal do doente, além de carregarem forte estigma. (OMS, 2001; CARVALHO, 2000). Estes transtornos estão entre os que mais aumentam a carga de doença, quantificado pelos anos potenciais de vida perdidos ajustados para incapacidade (OMS, 2001).

A maioria dos paciente foram diagnosticados e estão em tratamento há menos de cinco anos,sendo que oito pacientes estavam em sua primeira internação. Estudos recentes descrevem os primeiros anos de doenças psiquiátricas como um período em que os familiares e doentes necessitam de grande atenção e orientação sobre a doença mental e seu tratamento. (NEWSTEAD, 2003; VANMEIJEL, 2004).

Desde meados da década de 50, quando se propôs que o doente mental deveria ser tratado no meio onde viveu e adoeceu, a família passou a ser considerada a principal colaboradora nos cuidados com o adoecido mentalmente. Os períodos de hospitalização mais curtos como conseqüência do processo de desinstitucionalização psiquiátrica levou a família a se tornar, cada vez mais, a principal provedora de cuidados e apoio aos pacientes psiquiátricos. Apesar do aspecto positivo da promoção dos laços familiares e sociais essa responsabilização é marcada pela sobrecarga dos cuidadores (BANDEIRA E BARROSO, 2005). 
A manutenção do doente mental fora da instituição hospitalar causa grande impacto na família (ROSE, 1996; MELMAN 2001). A escala FBIS-BR foi aplicada aos familiares dos pacientes para analisar este impacto causado ao familiar após a alta hospitalar. Ao ser realizado um acompanhamento com os familiares dos pacientes egressos de internação psiquiátrica nos três primeiros meses os resultados apontaram que houve uma diminuição da sobrecarga do cuidado do primeiro para o terceiro mês

Ao analisar as respostas à FBIS-BR no primeiro e no terceiro mês após a alta hospitalar observa-se que das quatros subescalas (A, B, D e E) apenas nos escores médios da subescala E a sobrecarga subjetiva apresenta-se maior do que a objetiva, em todas as demais é indicado que os familiares apresentam uma maior sobrecarga objetiva do que subjetiva. Um exemplo citado é que no item A2b da escala o familiar é questionado se a supervisão de medicações, o prepara de alimentos e a locomoção do paciente (transporte) lhe causam incomodo, e a maioria respondeu pouco ou muito pouco, indicando baixa sobrecarga subjetiva.

Os baixos escores da medias sobrecarga subjetiva podem ser explicados pelo impacto da desejabilidade social, ou seja, uma propensão por parte dos familiares a responderem de forma tendenciosa ,mais aceitável ou aprovadas socialmente (RIBAS et. al. ,2004) .Muitas vezes os principais cuidadores vivenciam sentimentos de culpa em relação ao adoecimentos dos seus familiares gerando uma maior necessidade de aprovação e aceitação pela sociedade.(SCAFUZA, 2008; SILVA, SANTOS, 2009)

A sobrecarga familiar diminui do primeiro para o terceiro mês após a alta hospitalar. Três aspectos podem explicar esse resultado: 1- Paciente ainda apresenta sintomas da doença no primeiro mês após a alta hospitalar; 2- Readaptação da família após três meses de alta hospitalar 3 - Estratégia de visitas domiciliares.

Ao sair de uma internação psiquiátrica o doente pode apresentar sintomas agudos de seu transtorno mental. Alguns pacientes recebem alta hospitalar sem estarem em plenas condições de alta, apresentando por exemplos sintomas da doença. Após três meses, o tratamento medicamentoso pode ter melhorado os sintomas (a família supervisionou mais no inicio) e a família se readaptou com o familiar doente novamente em casa. O Item da escala D2 - Impacto permanente na vida do cuidador que indicou o alivio da sobrecarga permanente do impacto do paciente na rotina, demonstra este fato.

Outro evento importante a ser considerado para explicar a diminuição da sobrecarga familiar após três meses da alta hospitalar é a readaptação da família. Durante a internação a família pode se organizar para atender as necessidades do grupo que ficam pouco assistidas 
no cotidiano. Com a volta do doente para casa é necessário nova re-organização causando sobrecarga maior. Após três meses o grupo já está adaptado novamente e a sobrecarga diminui.

O acompanhamento realizados durantes os três meses a essas famílias pode ter colaborado para a diminuição das sobrecargas percebida por elas. Pois o contato com o pesquisador oferece esclarecimentos sobre a doença e tratamento ajudando os familiares a identificarem sintomas precocemente e desenvolvem estratégias para lidar com as mudanças na vida cotidiana. (LAIDLAW et. al., 2002) 


\section{6 - CONSIDERAÇÕES FINAIS}

O objetivo desta pesquisa foi descrever a sobrecarga do familiar cuidador de pacientes egressos de internação psiquiátrica no primeiro e no terceiro mês após a alta de internação psiquiátrica. O método adotado permitiu verificar diferenças na sobrecarga objetiva e subjetiva e diferenças entre o primeiro e o terceiro mês após a alta. Acompanhar as alterações na sobrecarga familiar pode ser útil para estabelecer momentos e tipos de intervenção durante o período imediato após a alta hospitalar.

Este estudo aponta para a importância e necessidade de acompanhamento dos pacientes egressos e seus familiares. A visita domiciliar é uma estratégia importante pois, consegue manter um vínculo mais estreito entre o doentes, sua família e o serviços de saúde mental; é parte das atividades do enfermeiro sendo portanto, um profissional da equipe que muito pode contribuir para melhorar as condições de doentes e famílias.

O enfermeiro tem posição privilegiada no contato com o doente e seus familiares, por isso mesmo, deve repensar sua prática para incluir a família. O papel da enfermagem é de suma importância e se destaca devido à grande proximidade de suas competências profissionais à demanda cotidiana dessa população. Além de desenvolver atividades de organização, planejamento, coordenação e execução dos serviços de cuidado, o profissional enfermeiro é o responsável pela administração, orientação e manutenção do tratamento medicamentoso. Essas ações objetivam organizar os serviços e oferecer uma assistência adequada às demandas de sua clientela. Este estudo contribuirá com novas pesquisas sobre o tema no intuito de proporcionar um atendimento de saúde adequado ao paciente psiquiátrico e seu familiar. 


\section{7 - REFERÊNCIAS BIBLIOGRÁFICAS}

1. AMARANTE, P.D, COUTINHO E.S.F. Perfil demográfico e sócio-econômico da população de internos dos hospitais psiquiátricos da cidade do Rio de Janeiro.Cad. Saúde Publica, Rio de Janeiro, 15(3):505-511,jul-set 1999.

2. ARANHA E SILVA A L; FONSECA, R.M.G.S. Processo de trabalho e saúde mental e o campo psicossocial, Revista Latino-Americana de Enfermagem, Ribeirão Preto.v13,n3,p 441-449,2005.

3. BARROSO S.M.; FREITAS, L. C. Family Burden Interview Scale for relatives of psychiatric patients (FBIS-BR): reliability study of the Brazilian version. Revista Brasileira de Psiquiatria (São Paulo), 2006. ; ISSN/ISBN: 1516446.

4. BARROSO S.M. Sobrecarga de familiares de pacientes psiquiátricos: fatores associados [Dissertação de Mestrado]. Belo Horizonte: Universidade Federal de Minas Gerais; 2006.

5. BARBOSA, G.C. Redes sociais de um grupo de portadores de esquizofrenia seguidos em um serviço de saúde mental na comunidade. 2011. Dissertação (Mestrado em Enfermagem Psiquiátrica) - Universidade de São Paulo.

6. BANDEIRA M; CALZAVARA M.G.P; VARELLA A.A.B. Escala de sobrecarga dos familiares de pacientes psiquiátricos: adaptação transcultural para o Brasil (FBISBR). Jornal Brasileiro de Psiquiatria, Rio de Janeiro, v. 54, n. 3, p. 206-214, 2005.

7. BANDEIRA M, BARROSO SM. Sobrecarga das famílias de pacientes psiquiátricos. J Bras Psiquiatr 2005; 54:34-46.

8. BRASIL. Ministério da Saúde. Secretaria de Atenção à Saúde. Departamento de Ações Programáticas Estratégicas. Saúde mental no SUS: os centros de atenção psicossocial / Ministério da Saúde, Secretaria de Atenção à Saúde, Departamento de Ações Programáticas Estratégicas. - Brasília: Ministério da Saúde, 2004. 86 p.: il. color. - (Série F. Comunicação e Educação em Saúde) ISBN 85-334-0775-0

9. CARDOSO, L. Recaídas em Pacientes Egressos de Internação Psiquiátrica - Um Olhar Sobre o Paciente e Sua Família. [Dissertação] São Paulo (SP): Escola de Enfermagem da USP; 2007.

10. CARDOSO, L. Egressos de internação psiquiátrica - um olhar sobre o paciente e seu familiar cuidador. 2008. 114f. TESE (Doutorado) - Escola de Enfermagem de Ribeirão Preto, Universidade de São Paulo, 2008. 
11. CARVALHO R.J.L., Utilização de Recursos e cursos diretos da esquizofrenia para o setor público do estado de São Paulo (Dissertação de Mestrado).Sao Paulo, UNIFESPEscola Paulista de Medicina; 2000.

12. COLVERO, L. A; IDE, C.A.C.; ROLIM, M. A. Família e doença mental: a difícil convivência com a diferença. Rev. Escola de Enf. USP, 2004; 38(2): 197-205.

13. COUTINHO, E.S.F., GOMES M.P.C., COUTO M.C.V, et. al.Censo de pacientes internados em uma instituição asilar no estado do Rio de Janeiro: dados preliminares. Caderno de Saúde Publica,2002 18:1803-7.

14. COUTINHO, E.S.F, ALMEIDA F., MARI J.J. Fatores de risco para a morbidade psiquiátrica menor. Resultados de um estudo trasnversal em três áreas urbanas no Brasil. Revista de Psiquiatria Clinica, São Paulo, 1999, vol.26, N 5 Pag 246-256.

15. CSERNASKY JG, SCHUCHART EK. Relapse and rehospitalisation rates in patients with schizophrenia: effects of second generation antipsychotics. CNS Drugs. 2002; 16 (7): 473-84.

16. DAVIS J.M, CHEN N. Choice of maintenance medication for schizophrenia. J Clin Psychiatry. 2003; 64 Suppl 16: 24-33.

17. DYCK, DG; Short, R; VITALIANO, PP. Predictors of Burden and infectious illness in Schizophrenia Caregivers. Psychosomatic Medicine (1999) 61: 411-419.

18. DOORNRBOS, M.M.-The problem and coping methods of caregivers of young a dults with mental illness. Journ of Psychosocial Nursing 35, 22-26, 1997.

19. DROULOUT T, LIRAUD F, VERDOUX H. Relaionships between insight and medication adherence in subjects with psychosis. Encephale 2003 Sep-Oct; 29(5); $430-7$

20. DUARTE, M.L.C.; SOUZA, J.; KANTORSKI, L.P.; PINHO, L.B. Diferentes abordagens à família em saúde mental presentes na produção científica da área. Rev. Min. Enf., v.11, n.1, p.66-72, jan/mar., 2007.

21. FALLON, I.R.H., BOYD, J.J.MCGILL, C.W. Family care of schizophrenia. New York. The Guilford Press, 1993.

22. FOLDEMO, A; GULLBERG, M; Ek, AC; BOGREN, L. Quality of life and burden in parents of outpatients with schizophrenia. Soc Psychiatry Psychiatr Epidemiol (2005) 40: 133-138. 
23. FELICIO, J. L; ALMEIDA, D.V. Abordagem terapêutica às famílias na reabilitação de pacientes internados em hospitais psiquiátricos: relato de experiência. $\mathrm{O}$ Mundo da Saúde São Paulo: 2008: abr/jun 32(2): 248-253.

24. FUKUDA IMK. O convívio com o paciente esquizofrênico, experiência dos familiares. São Paulo, 1989. 138. Tese (Doutorado)-Escola de Enfermagem da Universidade de São Paulo.

25. HERU, A.M; RYAN, C. Burden, reward and family functioning of caregivers for relatives with mood disorders: 1 - year follow-up. Journal of affective disorder. n. 83, p. 221-225, 2004.

26. JUNGBAUER J, et al. Subjective Burden Over 12 Months in Parents of Patients Whith Schizophrenia. Arch of Psychiatr Nursing 2003(June); XVII (3):126-134.

27. LAIDLAW, TM; COVERDALE, JH; FALLON, IRH, KYDD, RR. Caregivers' Stresses When Living Together or Apart from Patients with Chronic Schizophrenia. Community Mental Health Journal, Vol.38, No. 4, August 2002.

28. MAURIN JT, BOYD CB. Burden of mental illness on the family: a critical review. Archives of Psychiatric Nursing 4(2): 99-107, 1990.

29. MARCUS SC, OLFON M Outpatient Antipsychotic Treatment and Inpatient Costs of Schizophrenia. Schizophr Bull. 2007 Jun 19.

30. MARTINEZA; NADAL, S.; BEPERET, M., MENDIOROZ, P., Sobrecarga de los cuidadores familiares de pacientes com esquizofrenia-factores determinantes. ANALISES Sis San Navarra, 23(1) 101-110, 2000.

31. MALDONATO, JG; URÍZAR, AC; KAVANAGH, DJ. Burden of care and general health in families of patients with schizophrenia. Soc Psychiatry Psychiatr Epidemiol (2005) 40: 899-904.

32. MELMAN, J. Família e doença mental: repensando a relação entre profissionais de saúde familiares. São Paulo: Escrituras, 2001.

33. MELLO, R. A construção do cuidado à família e a consolidação da reforma psiquiátrica. Rev. enfermagem UERJ. 2005; 13(3): 390-395.

34. MOREnO, V; ALENCASTRE, MB. A trajetória da família do portador de sofrimento psíquico. Rev Esc Enferm USP 2003; 37(2): 43-50.

35. NEWTEAD L., KELLY M. Early intervention in psychosis: who wins, who loses, who pay the prices? Jornol of Psychiatric an Mental Health Nursing, 2003, 10, 83-88. 
36. KOGA M. Convivência com a pessoa esquizofrênica: sobrecarga familiar. [dissertação] Ribeirão Preto(SP): Escola de Enfermagem de Ribeirão Preto/USP; 1997.

37. PEJLERT, A. Being a parent of an adult son or daughter with severe mental illness receiving professional care: parent's narratives. Health and Social Care in the Community, v.9, n.4, p.194-204, 2001.

38. PERLICK DA, ROSENHECK RA, et al. Impact of family burden and affective response on clinical outcome among patients with bipolar disorder. Pychiatric services, v., 55, n. 9, p. 1029-1035, 2004.

39. POLIT D.F, BECK C.T; HUNGLER BP. Fundamentos de Pesquisa em Enfermagem: Método, Avaliação e Utilização. São Paulo: Artmed, 2004.

40. PROVENCHER, HL; MUESER, KT. Positive and negative symptom behaviours and caregiver burden in the relatives of persons with schizophrenia. Schizophrenia Research 26 (1997) 7180.

41. OLIVEIRA, MMB; JORGE, MSB. Doente Mental e sua relação com a família. In: Labate R.C. (Org.) Caminhando para assistência integral. Ribeirão Preto: Scaal, 1998, p. 379-388.

42. OLIVEIRA, L.H; MIRANDA, C.M.L. A instituição Psiquiátrica e o doente mental OTSUKA T, NAKANE Y, Ohta Y. Symptoms and social adjustment of schizophrenic patients as evaluated by family members. Acta Psychiatr Scand 1994; 89: 111-6.

43. OMS (Organização Mundial de Saúde), 2001. Relatório sobre a saúde no mundoSaúde Mental: Nova Concepção, Nova Esperança 2001.

44. RIBAS, R.C.; MOURA, M.L.S; HUTZ, R.S., Adaptação Brasileira da Escala de Desejabilidade Social de Marlowe-Crowne.Avaliaçao Psicológica. Itatba V.3, n.2, pag83-92, 2004.

45. ROSE, E. Families of psychiatric patients: a critical review and future research directions. Archives of Psychiatric Nursing, Vol X, No.2 (April), 1996, p.67-76.

46. RODRIGUEZ A, BRAVO MF. La Atención Integral en la Comunidad a las Personas con Trastorno Mental Grave. In Rehabilitación Psicosocial y Tratamiento Integral del Trastorno Mental Severo. 2003 Asociación Espanola de Neuropsiquiatria. 
47. ROBINSON D. G, WOERNER, M. G, DELMAN H. M, KANE J. M. Pharmacological Treatments for First-Episode Schizophrenia. Schizophr Bull 2005; 31: 705-722.

48. SAUNDERS, J.C.; BYRNE, M. A thematic analysis of families living with schizophrenia. Arch. Psychiatr. Nurs., v. 16, n. 5, p. 217-223,2002.

49. SAUNDERS JC. Families Living with severe mental Illness. Texas tech University, Lubbock, Texas, USA. Issues in Mental Health Nursing, 24: 175-198, 2003.

50. SAUNDRES JC. Walking a mile in their shoes: symbolic interactionism for families living with severe mental illness. Journal of Psychosocial Nursing 1997; 35(6):8-13.

51. SALlES, M. M.; BARROS, S. Reinternação em hospital psiquiátrico: a compreensão do processo saúde/doença na vivência do cotidiano / Readmission to a psychiatric hospital: the comprehension of the health/illness process through the experience of daily life. Rev. Esc. Enfermagem USP 2007; 41(1): 73-81.

52. SCAZUFCA, M. Brazilian version of the Burden Interview scale for the assessment of burden of care in carers of people with mental illnesses. Rev Bras Psiquiatria, $v$. 24, n. 1, p. 12-17, 2002.

53. SILVA, G; SANTOS M. A. Álbum de família e esquizofrenia: convivência em retrato. Psicologia em estudo. Maringá, vol 14, n.1 pag 83-91, jan.-mar. 2009.

54. TESCHINSKY, U. Living with schizophrenia: The family illness experience, Mental Health Nursing, ${ }^{\circ}$ 21, p. 387-396.

55. URIZAR, AC; MALDONATO, JG. Burden of care in families of patients with schizophrenia. Quality of Life Research (2006) 15: 719724.

56. WHO- World Health Organization the Tenth Revision of the International Classification of Diseases and Related Health Problems (ICD-10). 1992 Geneva: WHO.

57. VAN MEIJEL B, VAN DER GAAG M, SYLIAN RK, GRYPDONCK MHF. Recognition of early warning sings in patients with schizophrenia: a review of the literature. International Journal of Mental Health Nursing 2004; 13: 107-116.

58. VELTMAN, A; CAMERON, J.I; STWART, D.E. The experience of providing care to relatives with chronic mental illness. Journal New Mental Disorder, v.2, n.190, p. 108-114, 2002.

59. ZANETTI A.C.G. Cultural Adaptation and validation for Portuguese of Family. Questionnaire to evaluate the family environment of schizophrenic patients. 2010. 


\section{ANEXOS}

\section{Anexo 1 - Questionário sócio-demográfico e clínico de pacientes egressos de internação psiquiátrica.}

\section{QUESTIONÁRIO \\ (OBS: Para todas as questões $9=$ Informação ignorada)}

\section{Nome do paciente:}

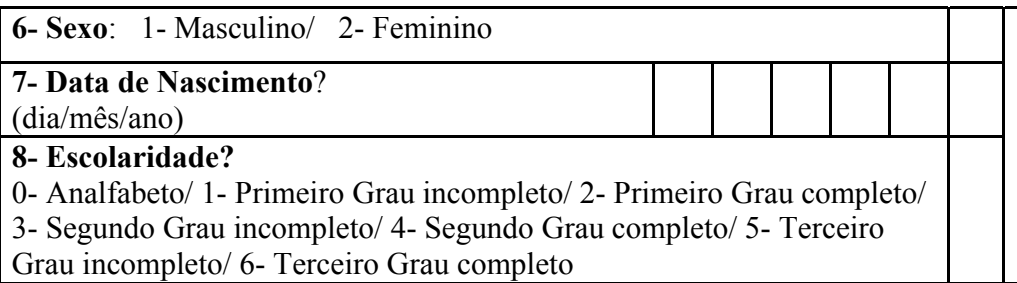

1. $\mathrm{N}^{\circ}$ sujeito banco:

2. $\mathrm{N}^{\mathrm{o}}$ (HYGIA) do paciente

3. Data coleta (dia/mês/ano)

4. Número da coleta

5- Local da entrevista: 1-NSM 2- Casa do paciente

9- Estado civil? 0 -Nunca se casou/amasiou/1-Separado (a)/2 2Casado ou Amasiado (a) / 3-Viúvo (a)/ 4-Divorciado (a)

10- Quantos filhos você (Paciente) tem?

0-Não tem/ 1-Um filho/ 2-Dois filhos/ 3-Três filhos ou mais
11- Você trabalha ou já trabalhou?

0- Nunca trabalhou/ 1- Desempregado/ 2-Faz trabalhos eventuais

("bicos")/ 3-Trabalho regular (informal) / 4-Trabalho regular (registrado)/ 5- Afastado do trabalho / 6- Aposentado INSS/ 7- Outra (........................).

12- Quanto você ganha por mês? 0-Não tem renda/ 1-Até um salário mínimo( $\mathrm{R} \$ 380,00) / 2$ 2-Até dois salários mínimos $(\mathrm{R} \$ 760,00) /$ 3-Até três salários mínimos $(\mathrm{R} \$ 1140,00) /$ 4-Mais de três salários.

13- Com quem você Paciente mora? 0-Mora sozinho/ 1-Com familiares/ 2-Com amigos/colegas/ 3-Asilo/ 4-Casa Assistida

(comunidade terapêutica)/ 5-Outra (.........................................)
14- A casa em que você mora é?:

1-Própria/ 2-Alugada/ 3-Cedida/Emprestada/ 4-Morador de instituição/ 5-Morador de rua/ 6-Outra(..................................)

15- Com quantas pessoas você Paciente mora? que coabitam na mesma residência):

16- Qual é a Renda Total da sua família? 0-Não tem/ 1-Até um salário mínimo( $\mathrm{R} \$ 380,00) / 2$ 2-Até dois salários mínimos $(\mathrm{R} \$$

760,00)/ 3-Até três salários mínimos (R\$ 1140,00)/ 4-Mais de três salários mínimos/ 5-não sabe dizer

\begin{tabular}{|l|ll|l|l|l|}
\hline 17-Diagnóstico psiquiátrico do & 17.1 Diagnostico 1 & $\mathrm{~F}$ & & & \\
\hline & 17.2 Diagnostico 2 & $\mathrm{F}$ & & & \\
\cline { 2 - 7 } $\begin{array}{l}\text { prontuário } \\
\text { colocar código CID 10; em ordem } \\
\text { crescente): }\end{array}$ & 17.3 Diagnostico 3 & $\mathrm{F}$ & & & \\
\hline & 17.4 Diagnostico 4 & $\mathrm{F}$ & & & \\
\hline
\end{tabular}

18- Você sabe dizer qual é o nome da doença psiquiátrica/ mental que você tem? 1 - Não / 2 - Sim

19- Você sabe dizer há quanto tempo você tem essa doença? (em anos completos) 0-Um ano/ 1-Dois anos/ 2-Três anos/ 3-Quatro anos/4-Cinco anos ou mais/ 5- não sabe dizer

20- Você acha o tratamento com remédios importante para melhorar sua saúde? 1 - Não / 2 - Sim

21- Você sabe dizer quais são os remédios que você está tomando atualmente (agora depois da internação)? 1-Não / 2-Parcialmente (alguns)/3- Sim (todos)

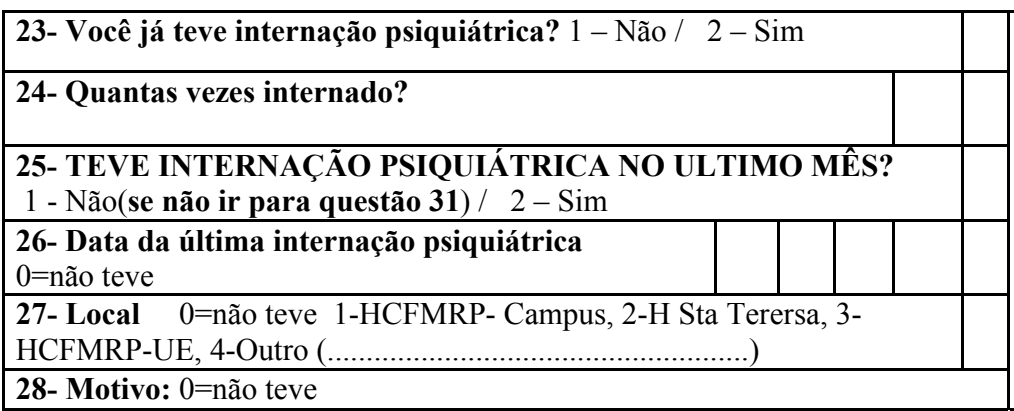

\begin{tabular}{|c|c|}
\hline \multirow{5}{*}{$\begin{array}{l}\text { 22- Classe de } \\
\text { Psicofármacos } \\
\text { prescritos: } \\
1 \text { - Não } \\
2 \text { - Sim }\end{array}$} & 28.1 Ansiolíticos e Hipnóticos \\
\hline & 28.2 Antidepressivos tricíclicos \\
\hline & 28.3 Antidepressivos ISRS \\
\hline & 28.4 Antidepressivos mistos \\
\hline & 28.5 Antipsicóticos Tipicos \\
\hline \multirow{4}{*}{$\begin{array}{l}\text { "Verificar a } \\
\text { prescrição médica } \\
\text { atual” }\end{array}$} & 28.6 Antipsicóticos Atipicos \\
\hline & 28.7 Estabilizadores do Humor \\
\hline & 28.8 Anticonvulsivantes \\
\hline & 28.9 Antiparkinsonianos \\
\hline OBS: & \\
\hline
\end{tabular}

29- Duração da última internação (dias): $0=$ não teve 30- Intervalo em dias entre a data de alta hospitalar e a ida do paciente ao serviço comunitário: $0=$ não teve 31- Precisou ir a um serviço de urgência/emergência psiquiátrica no ultimo mês? 1-Não 2-Sim OBS: 
32- Você alguma vez esquece de tomar seu(s) remédio(s)? 1 -

Não / $2-\operatorname{Sim}$

33- Você, as vezes, é descuidado com os horários de tomar seu remédio? 1 - Não / 2 - Sim
34- Quando você se sente bem, alguma vez, deixa de tomar seu remédio? 1 - Não / 2 - Sim

35- Quando você se sente mal, com o remédio, você as vezes deixa de tomar ele? 1 - Não / 2 - Sim

\begin{tabular}{|c|c|c|c|c|c|c|c|c|c|c|c|c|c|c|c|c|c|c|}
\hline BPR & (ques & es de & 6 a 54 & (escor & de $0 \mathrm{a}$ & & & & & & & & & & & & & \\
\hline 1-PS & 2-AP & 3-RE & 4-DC & 5-AC & 6-AS & 7-DM & 8-AEE & 9-HD & $\overline{10-H}$ & 11-D & 12-Al & 13-RP & 14-FC & 15-PI & 16-AE & 17-AP & 18-DC & TOTAL \\
\hline & & & & & & & & & & & & & & & & & & \\
\hline
\end{tabular}

55- O paciente possui um cuidador responsável? 1-Não/ 2-Sim (se sim preencher dados do cuidador e escala FBIS-BR) 


\section{Anexo 2 - Questionário sócio-demográfico e clínico de familiares cuidadores de pacientes egressos de internação psiquiátrica.}

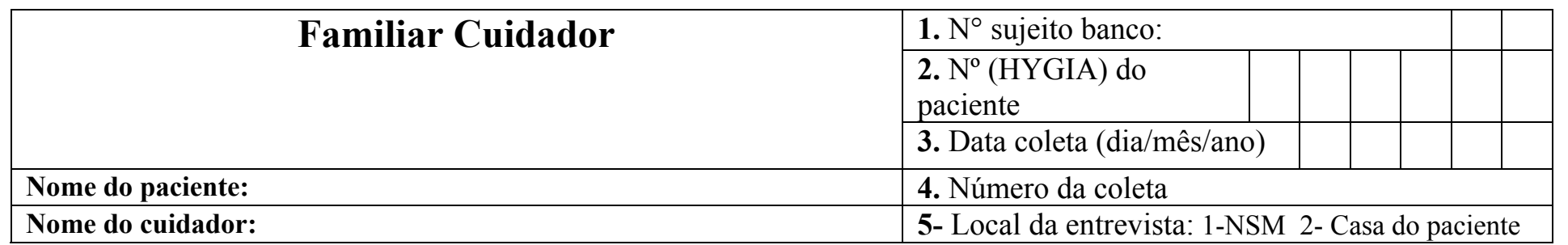

\begin{tabular}{|c|c|}
\hline 56- IDADE do cuidador: (anos completos) & $\begin{array}{l}\text { 59- Estado civil do cuidador } 0 \text {-Nunca se casou/ 1-Separado(a) / } \\
\text { 2-Casado ou Amasiado(a)/ 3- Viúvo(a)/ 4-Divorciado(a) }\end{array}$ \\
\hline $\begin{array}{l}\text { 58- Grau de escolaridade do cuidador: } \\
\text { 0-Analfabeto/ 1-Primeiro Grau incompleto/ 2-Primeiro Grau completo/ 3- } \\
\text { Segundo incompleto/ 4-Segundo completo/ 5-Terceiro incompleto/ 6- } \\
\text { Terceiro completo }\end{array}$ & $\begin{array}{l}\text { 61- Situação atual do cuidador quanto ao trabalho: } \\
\text { 0-Recebe pelo cuidado prestado/ 1-Nunca trabalhou/ 2-Desempregado/ 3- } \\
\text { Faz trabalhos eventuais ("bicos")/ 4-Trabalho regular (informal) / 5- } \\
\text { Trabalho regular (registrado)/ 6- Afastado do trabalho / 7- Aposentado } \\
\text { INSS 8- outra }\end{array}$ \\
\hline
\end{tabular}




\section{Anexo 3 - Escala de Avaliação da Sobrecarga dos familiares FBIS-BR}

PARTE A: ASSISTÊNCIA NA VIDA COTIDIANA : Geralmente as pessoas que têm doenças mentais precisam de ajuda ou precisam ser lembradas de fazer as coisas comuns do dia-a-dia. As perguntas que vou fazer agora são sobre isso. Talvez, nem todas elas se apliquem a (.......Nome..........), mas tente respondê-las, por favor, com o conhecimento que você tem sobre ele(a).

De A1a até A9a alternativas:1-Nenhuma vez/ 2-menos que uma vez p/ semana / 3- 1 ou 2 vezes p/ semana / 4- de 3 a 6 vezes p/semana / 5-Todos os dias

A1a. Nos últimos 30 dias, quantas vezes você ajudou (Nome) ou lembrou-lhe de fazer coisas como se pentear, tomar banho ou se vestir? Foram quantas vezes? 1-Nenhuma vez (PASSE P/ A2a)

A2a. Nos últimos 30 dias, quantas vezes você ajudou, lembrou ou encorajou (Nome) a tomar os remédios dele(a) ou teve que dar o remédio pessoalmente ou às escondidas? Foram quantas vezes? 1-Nenhuma vez (PASSE P/ A3a)

A3a.Nos últimos 30 dias, quantas vezes você ajudou (Nome) ou lembrou-lhe de fazer tarefas da casa (ex. arrumar a cama, limpar o quarto, lavar roupa, etc.) ou teve que fazer isto para ele(a)? Foram quantas vezes?

A4a. Nos últimos 30 dias, quantas vezes você ajudou (Nome) ou lembrou-lhe de fazer compras de alimentos, roupas ou outros objetos ou teve que fazer compras para ele(a)? Foram quantas vezes?

A5a. Nos últimos 30 dias, quantas vezes você cozinhou para (Nome) ou o (a) ajudou a preparar as refeições? Foram quantas vezes?

A6a. Nos últimos 30 dias, quantas vezes você ajudou a levar (Nome) a algum lugar, à pé, de carro, de ônibus ou por outros meios de transporte? Foram quantas vezes?

A7a. Nos últimos 30 dias, quantas vezes você ajudou (Nome) a cuidar do dinheiro dele(a) ou teve que fazer isso por ele/ela? Foram quantas vezes?

A8a. Nos últimos 30 dias, quantas vezes você ajudou, lembrou ou insistiu com (Nome) para ele(a) se ocupar com alguma coisa, não ficar à toa, usar o seu tempo para fazer alguma coisa, como ler revista, se divertir com alguma coisa, trabalhar, estudar ou visitar as pessoas, etc. ? Foram quantas vezes?

A9a. Nos últimos 30 dias, quantas vezes você lembrou, encorajou ou insistiu com (Nome) ou teve que levá-lo(a) para as suas consultas médicas ou atividades nos serviços de saúde mental? Foram quantas vezes?
De A1b até A9b alternativas:.1-Nem um pouco/ 2-muito pouco/ 3-um pouco/ 4-muito A1b. Quanto lhe incomodou ter que ajudar (Nome) ou lembrar-lhe de fazer essas coisas?

A2b. Quanto lhe incomodou ter que fazer alguma coisa para (Nome) tomar os remédios dele(a)?

A3b. Quanto lhe incomodou ter que ajudar, lembrar ou fazer essas coisas para ele(a)?

A4b.Quanto lhe incomodou ter que ajudar, lembrar ou fazer essas coisas para ele(a)?

A5b. Quanto lhe incomodou ter que cozinhar para (Nome) ou ajudá-lo(a) a preparar as refeições dele(a)?

A6b. Quanto lhe incomodou ter que ajudar a levar (Nome) a algum lugar?

A7b. Quanto lhe incomodou ter que ajudar (Nome) a cuidar do dinheiro dele(a) ou a fazer isto por ele(a)?

A8b. Quanto lhe incomodou ter que ajudar ou lembrar (Nome) a se ocupar com alguma coisa?

A9b. Quanto lhe incomodou ter que lembrar, encorajar ou levar (Nome) para as suas consultas médicas ou atividades nos serviços de saúde mental?

PARTE B: SUPERVISÃO AOS COMPORTAMENTOS PROBLEMÁTICOS: Algumas vezes, as pessoas com doenças mentais podem precisar de ajuda quando ocorrem alguns comportamentos problemáticos. As perguntas que vou fazer agora talvez não se apliquem a (Nome), mas tente respondê-las, por favor, com o conhecimento que você tem sobre ele (a).

De B1a até A8a alternativas: 1-Nenhuma vez/ 2-menos que uma vez p/ semana / 3- 1 ou 2 vezes $\mathrm{p} / \mathrm{semana} / 4$ - de 3 a 6 vezes $\mathrm{p} / \mathrm{semana} / 5$-Todos os dias

B1a. Nos últimos 30 dias, quantas vezes você tentou evitar ou impedir (Nome) de apresentar algum comportamento que te deixasse envergonhado(a) ou incomodado(a) ou teve que lidar com estes comportamentos ou com suas conseqüências ? Foram quantas vezes? Nenhuma vez (PASSE P/ B2a)

B2a. Nos últimos 30 dias, quantas vezes você tentou evitar ou impedir que (Nome) ficasse exigindo demais sua atenção ou você teve que lidar com este comportamento ou suas conseqüências? Foram quantas vezes? (Nenhuma vez PASSE P/ B3a)

B3a. Nos últimos 30 dias, quantas vezes você tentou evitar ou impedir que

(Nome) incomodasse as pessoas durante a noite ou teve que lidar com este comportamento ou com suas conseqüências? Foram quantas vezes? (Nenhuma vez PASSE P/ B4a)

B4a. Nos últimos 30 dias, quantas vezes você tentou evitar ou impedir que

(Nome) insultasse alguém, ameaçasse ou machucasse alguém ou teve que lidar com este comportamento ou suas conseqüências ? Foram quantas vezes? (Nenhuma vez PASSE P/ B5a)

B5a. Nos últimos 30 dias, quantas vezes você tentou evitar ou impedir (Nome) de falar em morrer, ou de falar em se matar, de ameaçar ou tentar se matar? Foram quantas vezes? (Nenhuma vez PASSE P/ B6a)

B6a. Nos últimos 30 dias, quantas vezes você tentou evitar ou impedir que (Nome) bebesse demais (bebidas alcoólicas) ou teve que lidar com as conseqüências deste comportamento? Foram quantas vezes? (PASSE P/ B7a)

B7a. Nos últimos 30 dias, quantas vezes você tentou evitar ou impedir que

(Nome) comesse ou bebesse demais (bebidas não alcoólicas, ex. café, xaropes, etc.) ou fumasse demais? Foram quantas vezes? (PASSE P/ B8a)

B8a. Nos últimos 30 dias, quantas vezes você tentou evitar ou impedir (Nome) de usar drogas (ilegais) ou teve

que lidar com as conseqüências deste comportamento? Foram quantas vezes? (PASSE P/ C1a)
De B1b até B8b alternativas:.1-Nem um pouco/ 2-muito pouco/ 3-um pouco/ 4-muito B1b. Quanto lhe incomodou ter que lidar com este comportamento desconcertante de (Nome)?

B2b. Quanto lhe incomodou ter que lidar com o comportamento de (Nome) de exigir que você dê atenção a ele(a)?

B3b. Quanto the incomodou ter que lidar com este comportamento perturbador de (Nome)?

B4b. Quanto the incomodou ter que fazer isso?

B5b. Quanto lhe incomodou estas conversas, ameaças ou tentativas de (Nome) de se matar ou de falar em morrer?

B6b.Quanto the incomodou o fato de (Nome) beber?

B7b. Quanto lhe incomodou ter que lidar com este comportamento de (Nome)?

B8b. Quanto lhe incomodou o fato de ( Nome ) usar drogas (ilegais)? 


\section{PARTE C: GASTOS FINANCEIROS}

C1. Nos últimos 30 dias, você, pessoalmente, pagou ou deu algum dinheiro seu à (Nome) para cobrir algumas despesas dele (a) e que ele não lhe tenha devolvido? 1-Não/ 2-Sim

$\begin{array}{llll}\text { C2. Nos últimos } 30 \text { dias, o paciente teve gastos com os itens abaixo? } & \text { 1-Não } & \text { 2-Sim } & \text { (...quanto....) }\end{array}$

\begin{tabular}{|l|l|l} 
A- Transporte (carro, combustível, ônibus,táxi, etc?) & & I- Cigarros? (..............................................)
\end{tabular}

$($.......................................)

B- Roupas e calçados? (........................................)

C- Trocados para pequenos gastos? (.................................................)

D- Moradia (aluguel, prestação da casa) ? (se ele mora com o paciente, peça-lhe para estimar a parcela desta despesa correspondente ao paciente)

E- Alimentação (se ele mora com o paciente, peça-lhe para estimar a parcela destas despesas correspondente ao paciente). (..............................)

F- Medicamentos ? (...................................................)

G- Tratamento de saúde mental ? (............................................)

H- Outros gastos médicos (dentista,fisioterapeuta,etc.)

$($......................................)

C3. Quantia com a qual o paciente contribuiu para as despesas mensais:

C4. Gastos da família com o paciente (diferença entre C2 e C3):

C5. No último ano, os gastos que você teve com (Nome) foram pesados para você com que freqüência?

1-Nunca/ 2-Raramente/ 3-Ás vezes/ 4-Freqüentemente/ 5-Sempre ou quase sempre.

PARTE D. IMPACTO NAS ROTINAS DIÁRIAS

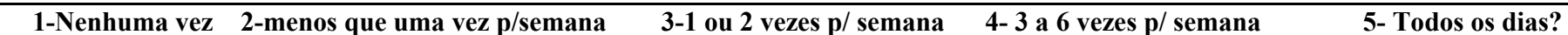

D1a. Nos últimos 30 dias, quantas vezes você faltou, chegou atrasado ou cancelou algum compromisso, como no trabalho, na escola ou em outros lugares, porque teve que cuidar de (Nome)? Foram quantas vezes?

D1b. Nos últimos 30 dias, quantas vezes as suas atividades sociais e de lazer (ex. sair para descansar ou visitar alguém) foram alteradas ou perturbadas, porque você teve que cuidar de (Nome)? Foram quantas vezes?

D1c. Nos últimos 30 dias, quantas vezes os seus serviços de casa, ou a rotina da casa, foi alterada ou perturbada porque você teve que cuidar de (Nome)? Foram quantas vezes?

D1d. Nos últimos 30 dias, quantas vezes o fato de cuidar de (Nome) impediu de você dedicar aos outros membros da família a atenção e o tempo de que eles necessitavam? Foram quantas vezes?

D2. A doença de (Nome) provocou mudanças mais ou menos permanentes na sua rotina diária, no seu trabalho ou na sua vida social? $\begin{array}{llll}\text { 1- Nem um pouco } & \text { 2- muito pouco } & 3 \text { - um pouco } & \text { 4-muito ? }\end{array}$

D3. Questões de A - F: Por causa da doença de........................................... (Nome):
A- Você teve que trabalhar menos ou abandonar o seu emprego ou teve que trabalhar mais para cobrir os gastos?

1-Sim ( ) 2-Não ( ). a

B- Você teve que se aposentar mais cedo do que você planejava?

b

C- Você deixou de ter (ou tem menos) vida social (ex.deixou de passear, visitar pessoas, ir a festas, etc.)?

$\mathrm{c}$

D- Você perdeu amizades?

d

E- Você deixou de tirar férias (ex. visitar parentes, viajar)?

e

F- Você deixou de receber (ou recebe menos) pessoas em casa (familiares e/ou amigos)?

f

PARTE E: PREOCUPAÇÃO COM O PACIENTE: Mesmo quando as pessoas não se vêem por algum tempo, às vezes, mesmo assim elas se preocupam umas com as outras. Eu gostaria de perguntar-lhe sobre suas preocupações com o(a).....

1- Nunca, 2- Raramente, 3- Às vezes, 4- Frequentemente, 5- Sempre ou quase sempre

E1. Você fica preocupado(a) com a segurança física de (Nome) (ex. que alguma coisa ruim aconteça com ele(a), que ele(a) sofra um acidente, entre em uma briga, que alguém se aproveite dele(a), que fuja, etc.):

E2. Você fica preocupado(a) com o tipo de ajuda e tratamento médico que (Nome) está recebendo ?(ex. com receio de que ele(a) não esteja sendo bem atendido(a), de que não esteja recebendo um bom tratamento para a doença dele(a), etc.?)

E3. Você fica preocupado(a) com a vida social de (Nome) (ex. preocupado se ele(a) não sai muito de casa, ou se sai demais ou se tem poucos amigos ou se sai com amigos que não lhe convém ?)

E4. Você fica preocupado(a) com a saúde física de (Nome)? (ex. dores, doenças, etc.)

E5. Você fica preocupado(a) com as condições de moradia atual de (Nome)?

E6.Você fica preocupado(a) ao pensar como (Nome) faria para sobreviver financeiramente se não houvesse você para ajudá-lo?

E7. Você fica preocupado(a) com o futuro de (Nome)? 


\section{Anexo 4 - Termo de Consentimento Livre, Esclarecimento \\ "SISTEMATIZAÇÃO DA COLETA DE INFORMAÇÕES RELEVANTES A MANUTENÇÃO DO TRATAMENTO EXTRA-HOSPITALAR DE PESSOAS COM TRANSTORNOS MENTAIS GRAVES"}

Pesquisadora responsável: Lucilene Cardoso

\section{ESCLARECIMENTO}

Nós profissionais da saúde estamos preocupados em melhorar nosso serviço para vocês e em entender como é para você e sua família o dia-a-dia com o tratamento da doença mental que você tem. Acreditamos que saber quais são as características do tratamento de pessoas como você e como você e seu familiar se sentem é importante para isso.

Na minha pesquisa vou conhecer como é seu tratamento fora do hospital e como sua família se sente. Para isso eu vou fazer algumas perguntas para você e para uma pessoa da sua família. Serão dois encontros um agora e um daqui a trinta dias quando vou fazer uma visita para você em sua casa, primeiro vou conversar com você e depois com seu familiar.

Nesses encontros vamos conversar e você e seu parente poderão ajudar na minha pesquisa. Aí vou juntar tudo o que você e seu familiar me contarem, com o que os outros pacientes me contarem, vou estudar tudo isso e fazer um trabalho final.

Se você e seu familiar concordarem em participar eu garanto que o nome de vocês não vai aparecer no meu trabalho em nenhum momento. Você não vai precisar pagar nada e também não vai receber dinheiro para participar. Sua participação não vai influenciar o seu atendimento aqui no serviço e você pode pedir para não participar do meu estudo quando você quiser, de acordo com a sua vontade. Eu prometo tirar qualquer dúvida que você tiver. Se você aceitar participar vou pedir que assine uma folha como essa que diz que você aceita e vou dar uma cópia para você guardar. 


\section{Termo de Consentimento Livre, Após Esclarecimento}

$\mathrm{Eu}$, (Paciente)

E eu (Familiar)

Entendi e ouvi da pesquisadora Lucilene Cardoso o que ela vai fazer na pesquisa: "SISTEMATIZAÇÃO DA COLETA DE INFORMAÇÕES RELEVANTES A MANUTENÇÃO DO TRATAMENTO EXTRA-HOSPITALAR DE PESSOAS COM TRANSTORNOS MENTAIS GRAVES" e eu ACEITO participar dessa pesquisa. Eu entendi que posso interromper ou parar a minha participação no estudo a qualquer hora em que eu quiser, sem precisar explicar o porquê e que isso não vai atrapalhar o tratamento oferecido nesse serviço de saúde mental. Sei que meu nome não vai aparecer no trabalho final, que não vou ter gastos e que não vou receber dinheiro para participar do estudo.

Ribeirão Preto, de de 2009.

Assinatura do paciente (ou impressão digital) e $\mathrm{n}^{0}$ Documento

Assinatura do responsável (ou impressão digital) e $\mathrm{n}^{0}$ Documento

Em qualquer caso de dúvida você pode entrar em contato comigo pelo telefone: (16) 3602-3442 ou 8124-6201 